\title{
O USO DE ÁCIDOS GRAXOS DE CADEIA CURTA NO CONTROLE DE SALMONELLA EM RAÇÕES DE AVES
}

\author{
ELIZABETH DE OLIVEIRA \\ Zootecnista
}

Orientador: Prof. Dr. Roberto Dias de Moraes e Silva

\begin{abstract}
Dissertação apresentada à Escola Superior de Agricultura "Luiz de Queiroz", da Universidade de São Paulo, para obtenção do título de Mestre em Agronomia, Área de Concentração: Ciência Animal e Pastagens.
\end{abstract}

PIR A C I C A B A

Estado de São Paulo - Brasil

Novembro - 1996 
Dados Internacionais de Catalogação na Publicação (CIP) DIVISĀO DE BIBLIOTECA E DOCUMENTAÇĀO - Campus "Luiz de Queiroz"/USP

Oliveira, Elizabeth de

O uso de ácidos graxos de cadeia curta no controle de salmonella em raçōes de aves / Elizabeth de Oliveira. - - Piracicaba, 1996.

71 p. : il.

Dissertaçāo (mestrado) - Escola Superior de Agricultura Luiz de Queiroz, 1997.

Bibliografia.

1. Ácido graxo 2. Ave doméstica 3. Raçāo (Contaminaçāo) 4. Salmonela Controle I. Titulo.

CDD 576.163 


\section{O USO DE ÁCIDOS GRAXOS DE CADEIA CURTA NO CONTROLE DE SALMONELLA EM RAÇŌES DE AVES}

ELIZABETH DE OLIVEIRA

Aprovada em: 19.02.97

Comissão julgadora:

Prof. Dr. Roberto Dias de Moraes e Silva

ESALQ/USP

Prof. Dr. Antônio Mário Penz Jr.

UFRGS

Prof. Dr. Joji Ariki

FCAVIUNESP

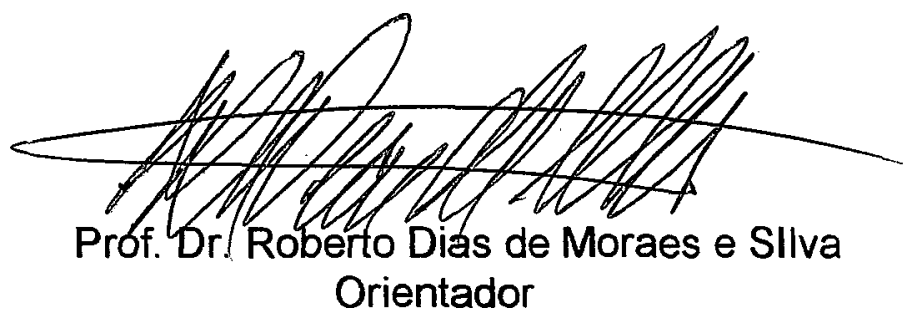


Aos meus pais José Vítor e Conceição, meus primeiros e eternos mestres, DEDICO.

À toda minha familia, principalmente aos meu cunhados Dilma e José Geraldo, pela acolhida durante o tempo em que estive em Piracicaba, a minha GRATIDÃO.

À meu esposo José Luís, pelo seu incentivo, compreensão, dedicação e amor, OFEREÇO. 


\section{AGRADECIMENTOS}

"O mais amplo do mundo, o conhecimento, o reconhecimento, a alegria deixada por um presente, como um suavíssimo cometa, tudo isto e muito mais cabem na extensão de uma palavra. Quando se diz obrigado, se dizem muitas coisas mais, que vêm de muito longe e muito perto, de tão longe como a origem do indivíduo humano, de tão perto como o secreto pulsar do coração."

(Pablo Neruda)

À Deus, pela possibilidade de estar terminando mais uma importante etapa em minha vida.

Ao Prof. Ângelo Berchieri Jr. co-orientador desse estudo, que com o seu grande conhecimento na área contribuiu de forma decisiva na elaboração e condução do mesmo, o meu muito obrigado.

Aos funcionários do Setor de Ornitopatologia da FCAVIUNESP, Aparecida Rodrigues Batista e Antônio José dos Santos, pelo auxílio no preparo do material e na condução dos experimentos.

À empresa Moinhos Primor pelo fornecimento do pintainhos utilizados nesse estudo.

À Fundação de Apoio à Pesquisa de São Paulo (FAPESP), por investir em mais um projeto de pesquisa.

À todos os colegas do curso de pós-graduação em Ciência Animal e Pastagens da ESALQ (turma de 1992), pelo tempo em que estivemos juntos.

Ao Prof. Roberto Dias de Moraes e Silva pela sua amizade, colaboração e estímulo para que esse estudo fosse realizado. 
À todos os professores do Departamento de Zootecnia da ESALQ, por compartilharem conosco os seus conhecimentos na área de nutrição animal.

À meu esposo José Luís, pela sua compreensão e ajuda no momentos mais difíceis.

... e a todos aqueles que direta ou indiretamente contribuiram para a realização desse estudo. 


\section{SUMÁRIO}

Página

RESUMO

vi

SUMMARY

viii

1 - INTRODUÇÃO

2 - REVISÃO DE LITERATURA

2.1 A Ração e os Ingredientes como Fontes de Salmonella ...

2.2 A Colonização do Intestino das Aves pela Salmonella ......

2.3 A Relação da Salmonelose em Aves e a Saúde Pública ...

2.4 O Controle de Salmonella em Rações e Matérias-primas...

2.4.1. Tratamento Térmico

2.4.2. O Uso de Ácidos Graxos de Cadeia Curta

2.5. Atividade Antibacteriana dos Ácidos Graxos de Cadeia Curta

3.1. Material

3.2. Métodos

4 - RESULTADOS

5 - DISCUSSÃO

6 - CONCLUSÃO

56

REFERÊNCIAS BIBLIOGRÁFICAS 


\title{
O USO DE ÁCIDOS GRAXOS DE CADEIA CURTA NO CONTROLE DE SALMONELLA EM RAÇÕES DE AVES
}

\author{
Autora : Elizabeth de Oliveira \\ Orientador : Prof. Dr. Roberto Dias de Moraes e Silva
}

\section{Resumo}

Para estudar o efeito dos ácidos graxos de cadeia curta (AGCC), também conhecidos como ácidos orgânicos, no controle de Salmonella em rações de aves, foram conduzidos oito experimentos, no Setor de Ornitopatologia, do Departamento de Patologia Veterinária, da Faculdade de Ciências Agrárias e Veterinárias de Jaboticabal da UNESP, no período de agosto de 1992 à fevereiro de 1994.

As cepas utilizadas foram Salmonella thyphimurium, Salmonella enteritidis, Salmonella infantis e Salmonella agona. Amostras de ração comercial, sem aditivos ou ingredientes de origem animal, foram esterilizadas e posteriormente inoculadas com as cepas acima descritas. Nos experimentos I e II, as rações foram tratadas com uma solução contendo os ácidos propiônico, fórmico e lático. Nos demais experimentos a solução utilizada foi composta somente pelos ácidos fórmico e propiônico.

Os tratamentos foram fornecidos a pintos de um dia de idade, por serem os mesmos mais susceptiveis à colonização por salmonelas. Após 72 horas, o conteúdo cecal das aves foi coletado e transferido individualmente para frascos esterilizados. A seguir foram preparadas seis diluições decimais seriadas que posteriormente foram semeadas em placas de Petri contendo Ágar Verde Brilhante e incubadas invertidas à $37^{\circ} \mathrm{C}$. A contagem de colônias de salmonelas foi efetuada após um período de 24 horas de incubação. 
A associação dos ácidos fórmico, propiônico e lático não se mostrou eficiente em eliminar a S. typhimurum in vitro ou in vivo (Experimentos I e II). Baseado em relatos da literatura científica foi desenvolvida uma nova associação contendo somente os ácidos fórmico e propiônico. Essa nova associação, quando adicionada à ração em uma proporção de $0,4 \%$, eliminou completamente o crescimento de $S$. thyphimurium e também atuou de forma eficiente sobre a $S$. agona. Entretanto, o crescimento de $S$. enteritidis somente foi controlado quando a concentração dessa solução de AGCC foi elevada a $0,8 \%$. A S. infantis demonstrou ser dose-dependende, ou seja, a solução de AGCC usada a $0,8 \%$ somente inibiu o crescimento deste sorotipo quando houve uma diminuição no número de bactérias inoculadas na ração. É importante ressaltar o comportamento diferenciado dos sorotipos utilizados nesses estudos, frente ao tratamento com a solução de AGCC.

Os resultados obtidos também sugerem a existência de um sinergismo entre os ácidos fórmico e propiônico, demonstrado pela maior eficiência dos mesmos sobre as salmonelas quando usados em associações, comparado às suas atividades quando adicionados individualmente às rações experimentais. 0 tratamento da farinha de carne, citada como sendo a principal fonte de contaminação em dietas para aves, com a solução de AGCC a $0,8 \%$ não foi eficiente no controle de Salmonella em rações para aves. $O$ tratamento da ração, de forma integral, demonstrou ser o meio mais eficaz de controle destes patógenos.

Os resultados demonstraram que uma solução contendo $70 \%$ de ácido fórmico e $30 \%$ de ácido propiônico foi eficiente sobre as salmonelas. Foram necessárias diferentes concentrações das soluções de AGCC, 0,4 e 0,8\%, para controlar o crescimento dos diferentes sorotipos de Salmonella. 


\title{
THE USE OF SELECTED SHORT-CHAIN FATTY ACIDS ON SALMONELLA CONTROL IN POULTRY FEEDS
}

\author{
Author : Elizabeth de Oliveira \\ Adviser : Prof. Roberto Dias de Moraes e Silva
}

Summary

To study the effects of selected short-chain fatty acids (SCFA) on Salmonella control in poultry feeds, eight experiments were carried out in the Ornitopathology Sector of the Veterinarian Pathology Department of Faculdade de Ciências Agrárias e Veterinárias de Jaboticabal - UNESP, from August 1992 to February 1994.

The strains of Salmonella used were Salmonella typhimurium, Salmonella enteritidis, Salmonella infantis and Salmonella agona. Sample of commercial poultry feeds, without additives or animal by-products added, were esterilized and inoculated with the Salmonella strains described above. The experimental rations were treated in the experiment I and II with a preparation of formic, propionic and lactic acids. The remaining experiments were treated with a preparation of SCFA containing formic acid and propionic acid.

Day-old chicks are more susceptible to the Salmonella colonization. So, day-old chicks were fed with the experimental diets. After 72 hours, the bird's cecal contends were removed and transferred to sterile glass rods. After that, six decimal dilutions were prepared, plating on Green Brilliant agar, incubated by 24 hours at $37^{\circ} \mathrm{C}$ and counted.

The preparation of formic, propionic and lactic acids did not reduce the recovery of Salmonella typhimurium in vitro or in vivo (Experiments I and II). Considering reports of the scientific literature another SCFA preparation with formic acid and propionic acid was developed. With $0.4 \%$ of this preparation, added in the experimental rations, no $S$. typhimurium was recovered in the bird's cecal contend. It was obseved the same effect on $S$. agona. However, the concentration had to be increased to $0.8 \%$ to eliminate the $S$. enteritidis growth. The serotype $S$. infantis showed to be dose-dependent. It means that for this serotype the action of the SCFA preparation is dependent on the number of bacterias inoculated in the ration, and also on the concentration of the preparation added. It is important to notice that different effects of the SCFA preparation were observed on each serotype utilized in this study. 
The results also suggested a synergism between formic and propionic acids. Added together on the rations they showed better efficiency against salmonellas than individually. The meat meal is considered the main source of Salmonella contamination in poultry feeds. However, the treatment with $0.8 \%$ of the SCFA did not show effect on salmonellae reduction. The treatment of the whole diet showed to be the best way to control salmonellae in poulty feeds.

The results of the experiments showed that a preparation of formic acid $(70 \%)$ and propionic acid (30\%) was effective against salmonellae. Different concentrations $(0.4$ or $0.8 \%$ ) were necessary to control the four serotypes used in this study. 


\section{1 - INTRODUÇÃO}

O gênero Salmonella pertence à familia Enterobacteriaceae. Existem mais de 2.300 sorotipos identificados. Alguns sorotipos são agentes de enfermidades específicas em aves, como por exemplo a Salmonella pullorum (agente etiológico da pulorose) e a Salmonella gallinarum (agente do tifo aviário). Todavia, a maioria dos sorotipos é capaz de infectar tanto o homem quanto os animais.

As salmonelas, hospedeiro não específico, são capazes de multiplicarem-se no trato entérico dos animais e seres humanos. As aves são bastante susceptiveis à infecção entérica, apresentam um quadro com sintomatologia variável, podendo ser severo e semelhante a pulorose ou sem sinais aparentes.

Como consequência do sistema intensivo adotado na avicultura industrial, as aves podem tornar-se veiculadoras de Salmonella entre si e para o ambiente, para outros animais e para os seres humanos. Animais portadores apresentam aumento da excreção fecal da bactéria mediante o uso de antimicrobianos na dieta (SMITH \& TUCKER, 1975), ou em situações de estresse como ocorre, por exemplo, durante o transporte para 0 abate (LINTON et al., 1985). Em aves adultas o aumento da excreção fecal pode acarretar a contaminação de ovos para o consumo ou para a incubação.

As aves jovens são altamente susceptiveis à colonização pela Salmonella, devido a falta de uma microflora intestinal adulta. A flora normal se estabelece durante as primeiras seis semanas, havendo um concomitante aumento na resistência à infecção por Salmonella. Deste modo, nas primeiras 96 horas de 
vida, niveis muito baixos de salmonelas podem colonizar o intestino de pintos (COX et al., 1990).

As infecções são rapidamente disseminadas para aves domésticas através da transmissão via ovo, de várias fontes ambientais naturais, incluindo os outros animais e o homem, e através do consumo de alimentos contaminados.

Muitos lotes de alimentos para aves são fontes de salmonelas. Essas bactérias uma vez ingeridas, através de alimentos contaminados, multiplicamse rapidamente no trato intestinal e se estabelecem altas populações nos portadores (WILLIAMS, 1981a).

BERCHIERI Jr. et al (1993b) revelaram que em 200 amostras de rações para aves proveniente de quatro fábricas diferentes, $10 \%$ estavam contaminadas com um, dois ou três sorotipos de Salmonella. Estes resultados estão de acordo com estudos anteriores onde foram detectadas presença de salmonelas em subprodutos de origem animal usados nas dietas de aves (BERCHIERI JR. et al, 1984 ; BERCHIERI et. al, 1989).

Os produtos de aves processadas contaminadas com Salmonella, também representam um problema importante em saúde pública (BORLAND,1975; ROBERTS,1988; HUMPHREY,1990; JOHN et al. ,1990). O perigo potencial de contaminação dos alimentos de consumo humano e o subsequente manejo inadequado na preparação dos mesmos faz com que as bactérias do gênero Salmonella sejam consideradas como uma das principais causas de contaminação dos alimentos (VILLEGAS, 1993).

A redução do número de salmonelas presente no alimento pode ser obtida pelo uso do calor durante a produção da ração, seja pelo processo de 
peletização ou pela irradiação (MclLROY et al., 1991). O calor gerado no processo de peletização é na maioria das vezes suficiente para eliminar salmonelas. Contudo, esta técnica apresenta a desvantagem de que o alimento pode ser recontaminado após o processamento, durante as operações de estocagem e distribuição.

Uma técnica alternativa é a de adicionar desinfetantes químicos ao alimento. Os agentes selecionados devem atender algumas exigências como as de não serem tóxicos nas concentrações utilizadas e permanecerem integros nos alimentos até que estes sejam consumidos (HINTON \& LINTON, 1988).

Os ácidos graxos de cadeia curta ou ácidos orgânicos, satisfazem estes critérios e o seu uso em raçōes para aves tem resultado na redução significativa do número de Enterobacteriaceae (VANDERWAL, 1979; HINTON et al. , 1985; HINTON \& LINTON, 1988; ROUSE et al.,1988; McHAN \& SHOTTS, 1992).

O objetivo do presente estudo foi o desenvolvimento de métodos e produtos para a eliminação da contaminação por Salmonella em rações e matériasprimas utilizadas na alimentação de aves, através do uso de ácidos graxos de cadeia curta. 


\section{2 - REVISÃO DE LITERATURA}

Foi considerado importante enfocar alguns aspectos da salmonelose de origem aviária, tais como a ração e as matérias-primas como principal fonte de contaminação em aves; a colonização da Salmonella no intestino; a relação da salmonelose e a saúde pública e os principais métodos de controle da Salmonella em alimentos fornecidos para aves destacando, principalmente, o uso de ácidos graxos de cadeia curta.

\section{1 - A Ração e os Ingredientes como Fontes de Salmonella}

É provável que as salmonelas têm estado presentes em alimentos de animais desde que estes foram domesticados (ELLIS, 1968).

ERWIN (1955) foi o primeiro a isolar Salmonella em alimentos comercialmente preparados e distribuidos para aves nos Estados Unidos. Ele examinou 206 amostras, incluindo alimentos farelados, peletizados, concentrados e triturados. Isolou Salmonella ou outro organismo entérico em $6 \%$ das amostras fareladas, $25 \%$ das amostras peletizadas, $15 \%$ das amostras de triturados e $61 \%$ das amostras de concentrados.

BOYER et al. (1958) isolaram Salmonella em amostras coletadas em fábricas de processamento de subprodutos que haviam sido cozidos previamente e estocados em pilhas abertas.

GALBRAITH (1961) associou um surto de infecção por salmonelas em aves na Inglaterra com a farinha de carne contaminada importada da América. 
Em 136 amostras de farelo de algodão, farelo de soja e mistura de ambos, foi observado que $5,1 \%$ estavam contaminadas com salmonelas, indicando que os ingredientes de origem vegetal também podem ser contaminados (GRUMBLES \& FLOWERS, 1961).

MOREHOUSE \& WEDMAN (1961), estudando 5.712 amostras de subprodutos de origem animal provenientes de 31 estados nos E.U.A., encontraram $12,6 \%$ destas contaminadas. Segundo os autores, a recontaminação dos subprodutos após 0 processamento foi 0 fator determinante para a presença de Salmonella.

Várias amostras de alimentos animais el ou ingredientes foram coletados por ISA et al. (1963), das quais $15 \%$ estavam contaminadas com Salmonella, sendo identificados 15 sorotipos diferentes.

CLISE \& SWECKER ${ }^{1}$ (1965), citados por WILLIAMS (1981a) encontraram 8 das 11 fábricas de subprodutos animais ou de farinha de sangue apresentando ingredientes contaminados por Salmonella. As aves ingerindo os ingredientes contaminados desenvolveram diarréia, sendo isoladas salmonelas na casca e gema de seus ovos.

De um total de 125 amostras de ingredientes protéicos analisados em uma fábrica de alimentos para animais, $27 \%$ continham um ou mais sorotipos de salmonelas, tendo sido identificados 41 sorotipos diferentes. A Salmonella estava presente em $14 \%$ dos sete lotes de rações destinados à alimentação das aves (VAUGHN et al., 1974).

' CLISE, J. D. \& SWECKER, E.E. . Salmonellae from animal by-products. Public Health Report, 80: 899, 1965. 
WATSON \& BROWN (1975) notaram uma relação direta entre salmonelas em alimentos para aves e aquelas encontradas em aves que os consumiram. Os autores também salientaram que a infecção poderia ser previnida pelo uso de alimentos não contaminados.

Segundo BORLAND (1975), existem inúmeras fontes de contaminação, mas provavelmente a mais importante é o alimento. Quase todos ingredientes usados na produção de alimentos animais têm mostrado conter uma vez ou outra salmonelas, mas estas bactérias ocorrem mais frequentemente em fontes de proteina animal, tais como farinha de carne e ossos, farinha de sangue e farinha de penas.

Segundo MARSH (1976) a desinfecção da ração e de seus ingredientes deveria ser colocada à frente de outras medidas de controle de Salmonella em aves.

HACKING et al. (1978) encontraram 4,3\%, das 93 amostras de rações peletizadas para frangos de corte analisadas, contaminadas por salmonelas.

MIRANDA et al. (1978) examinaram no Adolfo Lutz, em Campinas, S.P., 300 amostras de farinhas de carne, 68 de sangue, 8 de penas e 4 de peixe, provenientes de várias localidades do território nacional. Cerca de $40 \%$ das amostras de farinha de carne apresentaram-se contaminadas por Salmonella, sendo isoladas 118 cepas pertencentes a 23 sorotipos diferentes. As amostras de farinha de sangue, de penas e de peixe apresentaram, respectivamente, 21, 37 e $0 \%$ de contaminação por Salmonella.

Os ingredientes de rações estão frequentemente contaminados e o problema não está restrito aos constituintes do alimento de origem animal, mas também aos ingredientes de origem vegetal (VANDERWAL, 1979). 
BARBOUR \& NABBUT (1981) encontraram 5,0\% dos alimentos de uma granja de matrizes na Arábia Saudita contaminadas por Salmonella.

Amostras de rações para aves, fareladas e peletizadas, e de farinhas de carne e ossos foram coletadas em uma fábrica de rações. Foram isoladas salmonelas em 58, 0 e $92 \%$ das amostras fareladas, peletizadas e de farinha de carne, respectivamente (COX et al.,1983). As diferenças nas proporções de salmonelas obtidas por aqueles autores, comparadas às anteriormente descritas em outros estudos, podem ser atribuidas ao tamanho das amostras e à sensibilidade da metodologia de análise. Os autores concluiram que a transferência destes organismos da ração para as aves e destas ao homem se constitui em um importante risco de contaminação e infecção.

BERCHIERI Jr. et al. (1984) analisaram 204 amostras de farinhas de origem animal, usadas na produção de rações em três fábricas no Estado de São Paulo. Os resultados demonstraram que $39,16,63,33$ e $50 \%$ das farinhas de carne, penas, penas e vísceras, vísceras e farinha de ossos, estavam contaminadas por Salmonella.

Foram isoladas salmonelas em $19,5 \%$ de amostras de farinha de carne, $10 \%$ de farinha de penas e resíduos de incubatório e $7,7 \%$ de rações terminadas (GIRĀO et al., 1985).

Pesquisando a presença de Salmonella em uma granja comercial de frangos de corte, BERCHIERI et al. (1989) encontraram 22 sorotipos diferentes em amostras de farinha de carne, ração, fezes de ratos e "cama" de aves. A farinha de carne foi considerada a principal fonte de contaminação. 
JONES et al. (1991) conduziram um trabalho para examinar as fontes de contaminação por Salmonella na produção e no sistema de processamento de frangos de corte nos Estados Unidos. Os resultados obtidos demonstraram que a Salmonella foi mais frequentemente isolada no alimento e em seus ingredientes. Estes dados são semelhantes aos obtidos por MORRIS et al. (1969), ou seja, transcorridos mais de 20 anos o alimento continua sendo a principal fonte de contaminação para as aves.

Um estudo conduzido por BERCHIERI JR. et al, (1993b) revelou que de 200 amostras de rações, $10 \%$ estavam contaminadas com um, dois ou três sorotipos de Salmonella, com diferentes graus de contaminação entre os alimentos provenientes de diferentes fábricas de ração.

Os trabalhos apresentados demonstram que as rações e os ingredientes se constituem em uma das principais fontes de contaminação por salmonelas em aves. A adoção de medidas de descontaminação do alimento tem como objetivo a produção de animais que não se constituam em um risco potencial à saúde humana. 


\section{2 - A Colonização do Intestino de Aves pela Salmonella}

A superfície intestinal da maioria das espécies animais, incluindo as aves, é normalmente povoada por um grande número de bactérias, que estando associadas à mucosa do intestino resistem ao fluxo do alimento através do trato intestinal. A ligação da bactéria ao tecido do hospedeiro desempenha um papel central na habilidade destes organismos em colonizar a superfície mucosa e endotelial (McHAN et al., 1991).

A Salmonella paratífica não precisa estar associada ao epitélio. Geralmente quando isso ocorre é porque irá provocar infecção sistêmica. Após a fase de infecção, ela pode permanecer no conteúdo cecal.

Vários locais na superfície das células epiteliais atuam como receptores para a ligação de determinadas bactérias patógenas ao homem. A Salmonella em aves exibe uma predileção pela porção íleo caudal e cecos (McHAN et al.,1991).

Se a contaminação ocorre no alimento seco o número de bactérias normalmente é baixo, este pequeno número é capaz de colonizar o intestino de aves jovens, mas não o de aves adultas (NURMI \& RANTALA, 1973).

As aves jovens são altamente susceptiveis à colonização por salmonelas devido a ausência de uma microflora intestinal madura. Dessa maneira, baixos níveis desta bactéria, menos de uma célula/grama alimento, são suficientes para estabelecer colonização em pintos com um a sete dias de idade. Os pintos devem ser protegidos de uma exposição precoce devido a sua extrema susceptibilidade à infecções por Salmonella (XU et al., 1988 ; COX \& BAYLEY,1991). 
A resistência à infecção aumenta normalmente com a idade (McHAN et al., 1988). Em um lote infectado, a Salmonella enteritidis é capaz de estar infectando o tecido ovariano e pode ser isolada no trato alimentar de aves poedeiras clinicamente normais (LISTER, 1988).

Existem poucos casos de paratifo aviário diagnosticados em criações comerciais de frangos de corte. Entretanto, isto não significa que a ocorrência seja irrelevante. BERCHIERI et al. (1993a) diagnosticaram um surto de paratifo aviário causado por Salmonella typhimurium em um lote de frangos de corte de uma granja comercial. $\mathrm{O}$ aumento da mortalidade e da refugagem determinaram perdas econômicas.

Dentro das primeiras seis a sete semanas de idade, uma colonização bacteriana completa da parede cecal é adquirida, em aves livres de patógenos específicos, havendo uma predominância em aves maduras de lactobacillus. Contudo, a classe e o número de organismos no intestino de aves criadas convencionalmente é muito mais alta (COOPER, 1994).

O antagonismo microbiano entre a flora normal do intestino e patógenos invasores pode ser devido a produção de componentes que alterem os niveis de $\mathrm{pH}$ local ou pela competição por nutrientes disponiveis (BARROW et al., 1987). 


\section{3 - Relação da Salmonelose em Aves e a Saúde Pública}

O grau de contaminação de animais abatidos na Holanda é particularmente marcante em suínos e aves. Se a carne contaminada atinge a mesa do consumidor sem um tratamento térmico prévio, poderá ocorrer a infecção por Salmonella em seres humanos (VANDERWAL, 1979).

Segundo ROBERTS (1988), a salmonelose é uma indisposição intestinal, primeiramente causada pelo consumo de carnes e ovos contaminados. A maioria das pessoas com salmonelose acredita ter somente uma indisposição estomacal, sendo que a desinformação faz com que os consumidores não adotem medidas preventivas evitando os produtos contaminados.

Foi estimado um custo anual aproximado de um bilhão de dólares com os surtos de salmonelose humana nos E.U.A., isto levando-se em conta somente os custos médicos e as perdas na produtividade (ROBERTS, 1988).

Normalmente os consumidores de carne de aves conhecem pouco ou nada a respeito de como estes produtos são produzidos, processados e entregues aos postos de venda. Muitos ficariam surpresos ao saber que estes produtos contém uma microflora natural diversa incluindo bactérias, leveduras, fungos e vírus, e que alguns destes microorganismos podem ser, sob certas circunstâncias, patógenos ao homem (BAYLEY, 1988).

Em 1988, os ovos foram identificados como uma importante fonte de infecção por Salmonella enteritidis phage type 4 em seres humanos na Inglaterra, País de Gales e outros países da Europa. Quando presente na gema de ovos intactos, ela pode sobreviver à certas formas de cozimento. Na Inglaterra tem sido demonstrado que os surtos estão associados ao consumo de 
comidas elaboradas com ovos crus e molhos, como maioneses e alguns surtos também foram causados por pratos preparados com ovos cozidos (HUMPHREY,1990).

Um aumento na incidência de surtos de Salmonella enteritidis em seres humanos nos Estados Unidos nos anos 80 , focalizou a atenção sobre as possiveis fontes de infecção. As investigações identificaram o consumo de ovos ou alimentos contendo ovos como responsável por uma significativa proporção dos surtos (ALTEKRUSE et al.,1993; GAST \& BEARD, 1993).

Um envolvimento similar de ovos em surtos de $S$. enteritidis humana no Reino Unido resultou em uma queda no consumo de ovos, com devastadoras consequências econômicas para a indústria inglesa de ovos (GAST \& BEARD, 1993).

A incidência anual de salmonelose humana varia de 17,4 casos registrados para uma população de 100.000 pessoas nos E.U.A., 23,4 na Inglaterra e País de Gales, 27 na Austrália, 40,8 no Canadá e 77,1 na Alemanha Oriental (COOPER, 1994).

No Brasil os dados disponiveis são fornecidos por alguns levantamentos realizados pelos pesquisadores do Instituto Adolfo Lutz, somente no Estado de São Paulo. PESSÔA et al. (1978) observaram um surto epidêmico de S. typhimurium em São Paulo e chamaram a atenção para o alto percentual de resistência deste sorotipo a vários antimicrobianos testados. Em um levantamento epidemiológico compreendendo os anos de 1977-1988, 124 sorotipos diferentes de Salmonella foram isolados. Os sorotipos de origem humana prevalentes foram $S$. typhimurium $(69,3 \%), S$. agona $(16,11 \%)$ e $S$. typhi (3,03\%) (CALZADA et al., 1984). 
Um estudo relatando o padrão de incidência de diferentes sorotipos de salmonelas, isoladas no Instituto Adolfo Lutz no período de 1940 a 1990, demonstrou que a partir de 1968 houve um aumento da prevalência da S. typhimurium, a qual representou $77,7 \%$ de todos os sorotipos de origem humana isolados no período de 1970-76 (TAUNAY et al., 1996).

Registra-se em todo o mundo um aumento na incidência de toxinfecção alimentar, em particular de salmoneloses causada pela S. enteritidis. LíRIO et al. (1995) isolaram 42 cepas de Salmonella em alimentos na Seção de Microbiologia, Departamento de Inspeção Municipal de Alimentos, Secretaria Municipal de Abastecimento. Foram identificados 12 sorotipos, no Instituto Adolfo Lutz, sendo os mais frequentes $S$. enteritidis $(33,8 \%)$ e $S$. agona $(11,9 \%)$. Os alimentos que originaram o maior número de isolamentos foram o frango cru e a linguiça crua.

ARAÚJO et al. (1995) relataram quatro surtos causados por $S$. enteritidis e transmitidos por alimentos à base de ovos, principalmente pela maionese caseira. Os autores sugeriram um programa de informação à comunidade para impedir ou diminuir o consumo de ovos crus ou mal cozidos.

No abatedouro e na fase de processamento, as carcaças tornam-se frequentemente contaminadas e os alimentos preparados com estas carcaças são fontes de infecção para o homem (WILLIAMS,1981a; JOHN et al., 1990; DE ALMEIDA et al.,1993).

A presente tecnologia de processamento em abatedouros de aves não pode garantir um produto final livre de Salmonella. Assim, tem sido documentada a prevalência de contaminação em cerca de $80 \%$ das carcaças congeladas no 
Reino Unido e nos Estados Unidos acima de $50 \%$ dos produtos de aves crus (COOPER, 1994).

Todos os segmentos da indústria avicola trabalham seriamente para estar livres da contaminação microbiológica. Segundo MILES \& BUTCHER(1993) os consumidores deveriam ser avisados que frangos e ovos devem ser estocados sob refrigeração e cozidos adequadamente antes de serem consumidos.

Os produtos microbiologicamente inseguros serão fonte de perdas econômicas à indústria, contudo o maior prejudicado será o marketing, pela percepção do consumidor que os produtos de aves estão contaminados. 


\section{4 - O Controle de Salmonella em Rações ou Matérias-primas}

As salmonelas exigem para o seu crescimento temperaturas ambientais acima de $10^{\circ} \mathrm{C}$ e o pH ótimo está entre 6,5 e 7,5. Porém, são capazes de crescer em meios mais ácidos.

A redução da contaminação por Salmonella em alimentos envolve entre outras, duas possibilidades: o tratamento térmico e o tratamento com ácidos graxos de cadeia curta.

\subsection{1 - Tratamento Térmico}

Os subprodutos utilizados em rações animais podem sofrer a ação do calor durante o seu processamento. 0 aquecimento pode ser suficiente para eliminar as salmonelas, sem contudo alterar o valor nutritivo da proteína. 0 principal problema é previnir a recontaminação do alimento após o processamento, durante as práticas de transporte e distribuição do mesmo (WILLIAMS, 1981b).

O processo de peletização imprime à ração calor suficiente para destruir as salmonelas. Entretanto, alguns estudos deveriam ser conduzidos, segundo MARSH (1976), para explicar porque a peletização falha, algumas vezes, na eliminação destas bactérias.

QUADRI (1970)', citado por WILLIAMS (1981b), encontrou algumas amostras de alimentos peletizados contendo salmonelas. Porém, as amostras peletizadas a uma temperatura de $70-80^{\circ} \mathrm{C}$, apresentaram uma redução de $99,9 \%$ no número mais provável (NMP) de salmonelas quando comparadas 
com amostras não peletizadas. Vários trabalhos demonstraram que a temperatura empregada no processo de peletização da ração é o suficiente para eliminar a Salmonella (VANDERWAL, 1979; JOHN et al., 1990 ; McILROY et al., 1991). Na prática, a desvantagem do uso da peletização é uma possivel recontaminação da ração durante o periodo de estocagem, transporte e distribuição aos animais, devido a inadequada separação entre os produtos acabados e as matérias-primas cruas.

O processo de irradiação tem sido estudado e parece ser uma altemativa promissora. A idéia é submeter os produtos acabados de aves à irradiação. Porém, este processo apresenta custo elevado e existem ainda algumas controvérsias quanto a sua utilização.

1 QUADRI, S. F. . Effect of temperature, pelleting and some chemicals on the biological contamination of feeds. Manhatan, Kansas, 1971. (M. S. Thesis, Kansas State University). 


\subsection{2 - O Uso de Ácidos Graxos de Cadeia Curta}

LEVINE \& FELLERS (1940) observaram que o ácido acético inibiu ou destruiu a Salmonella aertrycke em um meio de $\mathrm{pH} 4,9$, sendo mais tóxico do que os ácidos lático e clorídrico, também estudados.

A colonização da Salmonella typhimurium em frangos tem se mostrado afetada por certos carboidratos da dieta (CORRIER et al., 1990; DELOACH et al., 1990; SHANE, 1992). A D-manose, em estudos in vitro, interfere na aderência da Salmonella typhimurium ao epitélio intestinal das aves. A lactose reduz o pH do ceco e promove o crescimento de bactérias acidúricas. Os ácidos graxos voláteis produzidos pelos organismos anaeróbios têm um efeito bacteriostático contra a Salmonella.

CORRIER et al.(1990) observaram que grupos de pintos de corte recebendo lactose apresentavam um $\mathrm{pH}$ intestinal menor que $\mathrm{o} \mathrm{pH}$ de pintos não recebendo este açúcar. As concentrações dos ácidos acético e propiônico aumentaram significativamente na presença da lactose. Estas observações foram confirmadas por McHAN (1991).

Ao longo dos anos tem sido estabelecido que os ácidos graxos voláteis exercem um efeito inibitório sobre um grande número de espécies bacterianas. A diminuição do pH da dieta através do uso dos ácidos fórmico, acético, propiônico e lático parece destruir as salmonelas ou inibir o seu crescimento.

GOEPFERT \& HICKS (1969), estudando as atividades dos ácidos fórmico, acético, propiônico e butírico sobre a $S$. typhimurium, observaram que a eficiência diminuia à medida que $\mathrm{opH}$ do meio fosse aumentado. Aqueles 
resultados sustentam a hipótese que a porção bactericida dos ácidos é a molécula não dissociada. O comprimento da cadeia, concentração e temperatura também influenciou na eficiência dos mesmos.

A adição de material graxo, contendo ácidos graxos voláteis com baixo peso molecular, exerceu efeitos inibitórios e em alguns casos efeitos bactericidas contra a Salmonella em farinha de carne e ossos (KHAN \& KATAMAY, 1969).

CHUNG \& GOEPFERT (1970), analisando diferentes ácidos, dividiram os mesmos em três grupos com base na tolerância da Salmonella à estas moléculas. Os ácidos graxos voláteis de cadeia curta, acético e propiônico, estavam no grupo dos ácidos mais restritivos, com $\mathrm{pH}$ de 5,4 e 5,5, respectivamente.

Um aditivo químico baseado em ácido propiônico foi adicionado em rações esterilizadas e não esterilizadas. Nas rações não esterilizadas com niveis de Salmonella acima de $\mathbf{2 . 0 0 0}$ organismos/g, não foi observado efeito inibitório significativo, mas nas rações esterilizadas houve uma completa inibição no crescimento (WESTERFELD et al., 1970).

Em um outro trabalho, DUNCAN \& ADAMS (1972) observaram um pequeno efeito de um aditivo químico comercial, cujos ingredientes ativos eram ácido propiônico, álcool isopropil e ácido fosfórico, sobre populações de salmonelas em rações de aves.

SMYSER \& SNOEYENBOS (1979) relataram que os niveis de formalina acima de $0,1 \%$ foram efetivos na prevenção da multiplicação de salmonelas em farinha de carne e ossos, contudo a formalina não é aprovada pelo Food and Drug Administration (F.D.A.). 
Os efeitos dos ácidos propiônico, acético e fórmico foram testados por VANDERWAL (1979), sendo que o número de dias exigido para uma redução decimal de Salmonella nos alimentos foi menor para o ácido fórmico. Os ácidos propiônico e fórmico e combinações dos mesmos provaram ser igualmente eficientes em niveis de $1,0 \%$.

Um outro efeito benéfico do tratamento com os ácidos é obtido pela eliminação de fungos (PASTER,1979; DIXON \& HAMILTON ,1981; SCHULTZ et al., 1991).

HINTON et al. (1985), não conseguiram isolar Salmonella em aves que receberam dietas que continham 0,5 e $0,75 \%$ de ácido fórmico. Os resultados indicaram que a adição de uma concentração relativamente baixa de um ácido orgânico foi capaz de inibir o crescimento destas bactérias em pintos.

Foi necessário um período superior à duas horas e inferior à 24 horas para eliminar eficientemente salmonelas em alimentos não esterilizados, tratados com um aditivo químico baseado em ácido propiônico, nas dosagens de 0,25, $0,50,0,75$ e 1,0\%, quando foram usados baixos niveis de inoculação (ROUSE et al., 1988) .

HINTON \& LINTON (1988) testaram dois produtos comerciais, um deles à base de ácido fórmico e o outro uma mistura dos ácidos fórmico e propiônico. Os resultados obtidos indicaram que o tratamento foi eficiente no controle de infecções quando o alimento foi contaminado tanto antes, quanto após a adição dos ácidos.

HUMPHREY\& LANNING (1988) descreveram vários experimentos envolvendo o tratamento do alimento fornecido à frangos de corte. Utilizando o ácido fórmico ou uma mistura de ácidos fórmico e propiônico. A vantagem da 
mistura destes ácidos é que eles atuam sinergicamente in vitro e são mais eficientes associados, do que quando utilizados separadamente (HINTON \& LINTON , 1988).

Em um estudo realizado por CHERRINGTON et al. (1991), o ácido propiônico foi um agente bactericida mais eficiente do que o ácido fórmico, provavelmente porque em pH 5,0 uma maior porção das moléculas do ácido propiônico está na forma não dissociada comparada ao ácido fórmico, $43 \%$ e $5 \%$, respectivamente.

Os ácidos lático e acético e o produto comercial BioAdd, mistura dos ácidos fórmico e propiônico, foram testados em diferentes temperaturas e na presença de material orgânico para a atividade antibacteriana contra Salmonella. O BioAdd foi o mais efetivo de todas as soluções em todas as temperaturas, seguido pelo ácido lático e ácido acético (CHERRINGTON et al. (1992).

McHAN \& SHOTTS (1992) relataram que aos sete dias de idade os ácidos fórmico e propiônico, em uma concentração de 1\% na ração, foram eficientes na redução da $S$. typhimurium por aproximadamente 1,4 log. Aos 21 dias a redução foi de 3,6 log para ambos os ácidos, quando comparados ao grupo controle.

Um estudo in vitro, conduzido por McHAN \& SHOTTS (1993), confirmou os resultados obtidos anteriormente por outros autores, onde o crescimento microbiano foi eliminado ou drasticamente reduzido pelo uso de ácidos graxos de cadeia curta. 
Os resultados de muitos trabalhos têm demonstrado que a inclusão de concentrações relativamente baixas de um ácido graxo de cadeia curta é capaz de eliminar salmonelas em pintos em crescimento. Este tipo de controle de Salmonella em alimentos de aves apresenta algumas vantagens:

- A adição dos ácidos graxos de cadeia curta à ração é relativamente simples, exigindo poucas modificações técnicas nos equipamentos da fábrica de rações;

- A ação dos ácidos provavelmente persista e este permaneça efetivo contra recontaminações subsequentes;

- As rações tratadas podem ser fornecidas até o momento de abate das aves, uma vez que não existe um período de retirada para ácidos graxos de cadeia curta, tais como o ácido fórmico (HINTON et al., 1985).

As diferenças observadas nos inúmeros trabalhos que analisam a influência de aditivos no crescimento das salmonelas são atribuidas por LINTON et al. (1985) aos diferentes modelos experimentais empregados.

HUME et al. (1992) e HUME et al. (1993b), estudando o efeito do ácido propiônico, na forma de um produto comercial pó ou na forma líquida, sobre a colonização da Salmonella typhimurium no papo e cecos de pintos de corte, não observaram efeito do mesmo reduzindo a infecção por Salmonella.

KANIAWATI et al. (1992) conduziram um estudo para observar o efeito da suplementação da dieta com os ácidos fumárico, lático e uma mistura dos ácidos fórmico e propiônico sobre o desempenho e a contaminação dos cecos e carcaça com $S$. typhimurium em frangos de corte. Observaram que nenhum dos tratamentos com ácidos forneceu consistente proteção contra a colonização por salmonelas nos cecos ou resultou em carcaças com menor 
grau de contaminação. Nenhum efeito adverso foi observado no desempenho das aves.

Em um outro estudo conduzido por OPITZ et al. (1993), nenhum dos cinco aditivos alimentares utilizados (Lactobacillus, lactose, ácidos orgânicos, múltiplos probióticos e pó de ovo) preveniu a colonização ou a invasão de órgãos de pintos da linhagem White Leghorn pela S. enteritidis, quando comparados ao grupo controle.

Pode ser observado em vários trabalhos empregando os ácidos orgânicos para o controle de Salmonella em rações de aves, que estes compostos são mais eficientes na forma líquida do que na forma de sal (pó seco).

Alguns autores têm estudado o efeito da adição dos ácidos orgânicos sobre o desempenho das aves. PATTEN \& WALDROUP (1988) demonstraram efeitos negativos do formiato de cálcio e efeitos positivos do ácido fumárico no crescimento e na eficiência alimentar de frangos, quando comparados nos mesmos niveis de adição $(0,5$ e 1,0\%).

IZAT et al. (1990a), não observaram efeitos adversos no desempenho de aves alimentadas com niveis de até $1,0 \%$ de ácido fórmico ou $1,45 \%$ de formiato de cálcio. Ainda IZAT et al. (1990b), estudando a influência de um aditivo baseado em ácido propiônico no desempenho de frangos de corte, não observaram efeitos adversos no crescimento, na eficiência alimentar ou na gordura abdominal. 


\section{5 - Atividade antibacteriana dos ácidos graxos de cadeia curta.}

Existe uma hipótese sobre o estágio no qual os ácidos passariam a exercer o seu efeito antibacteriano, o qual seria após a ingestão do alimento, quando este se torna hidratado (HINTON \& LINTON, 1988).

A atividade antibacteriana dos ácidos orgânicos é influenciada pela temperatura, concentração e dissociação, sendo esta última dependente da atividade de água do ambiente e do pH. $\mathrm{O}$ modo de ação não está totalmente elucidado, mas as hipóteses descritas abaixo são propostas por estudos realizados na Universidade de Bristol, na Inglaterra.

Os ácidos orgânicos não causam lise celular, ou pertubação na membrana celular, mas seguindo a difusão dentro da célula a molécula do ácido se dissocia em ânion e próton porque $\mathrm{o} \mathrm{pH}$ do citoplasma é alcalino. A consequente queda no $\mathrm{pH}$ citoplasmático inibe a síntese de várias macromoléculas como dos componentes da membrana celular, DNA, lipídios, RNA e proteina.

Estudos in vitro demonstraram ser o DNA o mais susceptivel à ação dos ácidos orgânicos(CHERRINGTON et al., 1990). Para restaurar o pH interno, a célula inicia uma ativa eliminação de prótons. Se existe insuficiente ATP, adenosina trifosfato, para concluir esta eliminação, a célula é irreversivelmente inibida pela desnaturação das proteinas ácido-lábeis. Entretanto, se as funções biossintéticas são recuperadas, os ânions são metabolizados e a divisão celular pode recomeçar (HINTON, 1990). 
Os alimentos comerciais apresentam quantidade insuficiente de àgua disponivel para a bactéria ser ativamente metabolizada e, consequentemente, os ácidos ou os seus sais parecem ser inativos ou relativamente inativos nos mesmos. A situação se modifica logo que o alimento é ingerido pela ave e é aquecido e umedecido no papo (HINTON, 1990; MOHAMMED \& HINTON, 1993).

HUME et al. (1993a) conduziram um estudo com o objetivo de determinar o destino do ácido propiônico no trato digestivo de pintos de corte. Os resultados demonstraram que o ácido propiônico da dieta é metabolizado e absorvido na porção anterior do intestino e não atinge o intestino ou cecos em quantidades apreciáveis. Os autores concluíram que é improvável que o ácido propiônico da dieta atinja o trato gástrico posterior de maneira suficiente a criar um ambiente efetivo contra as salmonelas. Recomendam que um controle efetivo de Salmonella em aves, deveria associar o uso de ácido propiônico na dieta com uma segunda prática de controle, como por exemplo a competição exclusiva, que consiste no fornecimento de microflora normal às aves jovens (NURMI \& RANTALA, 1973). 


\section{3 - Material e Métodos}

Os experimentos foram conduzidos no Setor de Ornitopatologia, do Departamento de Patologia Veterinária da Faculdade de Ciências Agrárias e Veterinárias de Jaboticabal da UNESP, no periodo de agosto de 1992 à fevereiro de 1994.

\section{1 - Material}

Bactéria: Nos experimentos I a V foi utilizada uma cepa de Salmonella typhimurium $\mathrm{F98}$, resistente ao ácido nalidixico e à espectinomicina, Nalr/Spcr. Nos experimentos VI, VII e VIII foram utilizadas cepas de S. agona, S. enteritidis e S. infantis, também $\mathrm{Nal}^{\mathrm{r}} / \mathrm{Spec}^{\mathrm{r}}$. Os inóculos consistiam de culturas destas bactérias preparadas em frascos contendo $10 \mathrm{ml}$ de caldo nutriente, incubados a $37^{\circ} \mathrm{C}$, por 24 horas, em banho-maria com agitação (100 movimentos por minuto).

Ração: Foi empregada uma ração comercial para frangos de corte, na fase inicial na proporção de $2 \mathrm{~kg}$ de raçāo por tratamento, sem aditivos e sem matéria-prima de origem animal. A cultura bacteriana $(1 \mathrm{ml})$ foi adicionada a um quilograma de ração, previamente esterilizada em autoclave, durante 20 minutos, à $121^{\circ} \mathrm{C}$. A mistura foi realizada aos poucos em um graal. A concentração final foi de aproximadamente $1,2 \times 10^{5}$ unidades formadoras de colônia por grama de ração (ufc/g). 
Ácidos Graxos de Cadeia Curta : Os ácidos utilizados para o tratamento das rações nos diferentes experimentos foram produtos puros para análise, P.A..

Tratamento com a solução de ácidos graxos de cadeia curta : Após a inoculação, as rações dos experimentos I e II foram levadas à um misturador elétrico, para receber o tratamento com os ácidos graxos de cadeia curta. A partir do terceiro experimento, foi adotada uma técnica diferente para misturar os ácidos pois o misturador elétrico apresentou problemas de manejo e funcionamento. Foi usado um pulverizador de jardim, onde as soluções de ácidos graxos de cadeia curta, AGCC, foram dosadas e posteriormente pulverizadas sobre a superfície das rações dispostas em sacos plásticos com capacidade aproximada de três a quatro vezes o seu volume; possibilitando que a ração ficasse bem espalhada, para que houvesse um bom contato dos ácidos pulverizados sobre a superfície da mesma. A seguir os sacos foram fechados e a homogeneização foi feita manualmente, provocando movimento rotatórios para que a solução de ácidos pudesse entrar em contato com toda a ração presente nos sacos plásticos.

As rações foram tratadas 48 horas antes de fornecê-las aos pintainhos. Em todos os estudos, o tratamento controle foi uma ração contaminada por Salmonella sem um posterior tratamento com a solução de AGCC.

Aves e alojamento: Foram usados pintainhos de corte imediatamente após a eclosão, da linhagem Hubbard, não sexados. Foram alojados 10 pintainhos por tratamento, em caixas de madeira contendo dois comedouros tipo cocho e um bebedouro de pressão previamente esterilizados (Fig. 1). As dimensões das caixas foram de $28 \mathrm{~cm}$ de altura, $42 \mathrm{~cm}$ de largura e $62 \mathrm{~cm}$ de comprimento, e foram fechadas por uma tampa telada com $10 \mathrm{~cm}$ de altura . $O$ aquecimento das 
aves foi realizado por uma lâmpada de 100 elou 150 watts posicionada sobre cada caixa (Fig. 2). As caixas ficaram em uma sala previamente desinfetada, totalmente fechada e com o acesso controlado.

Após o alojamento das aves, as rações e a água esterilizada, foram fornecidas a vontade aos pintainhos dos diferentes tratamentos. $O$ acesso à sala foi restrito somente à observação e para o suprimento de água e de ração. 


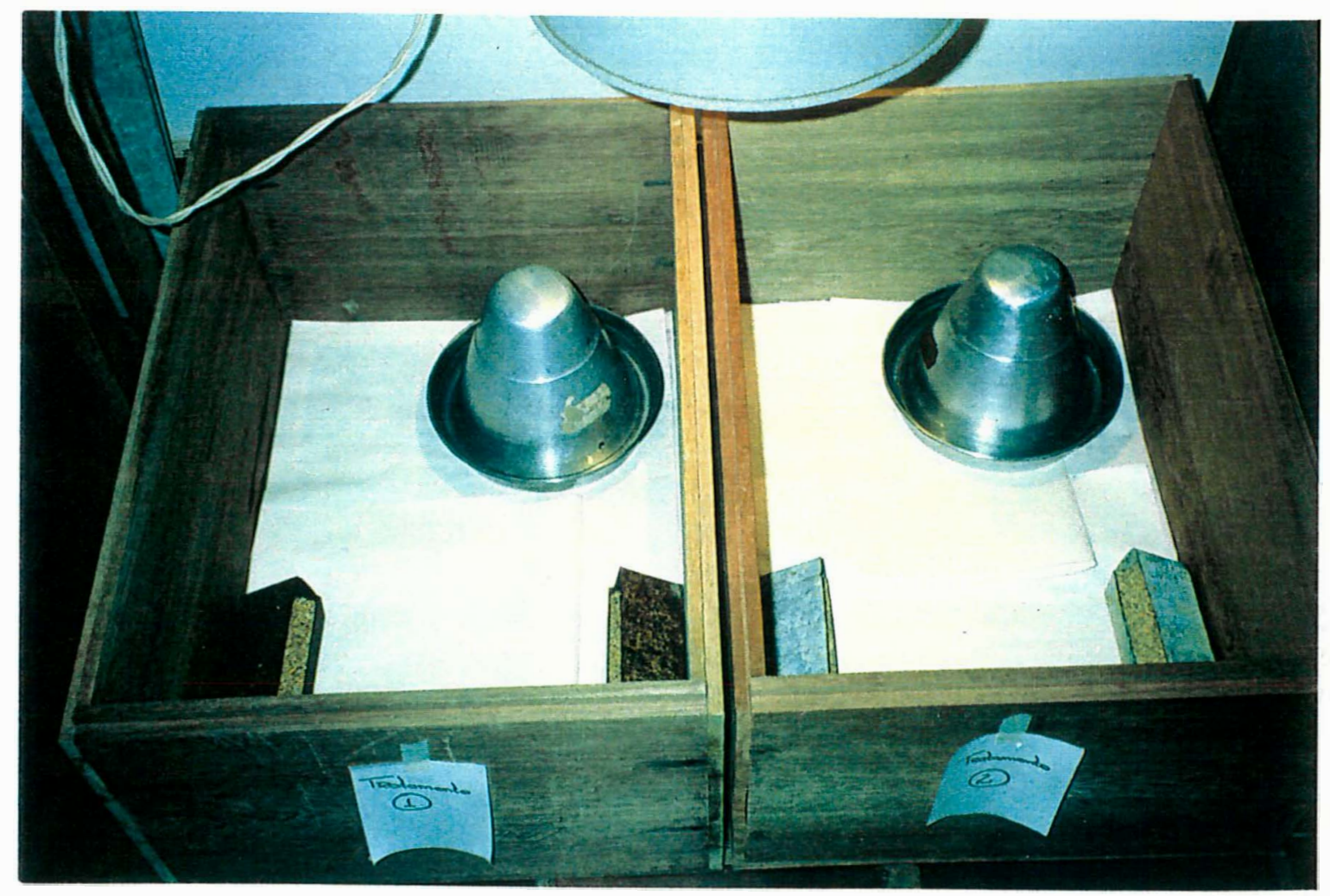

FIGURA 1 - Disposição dos comedouros e bebedouro nas caixas de madeira. 


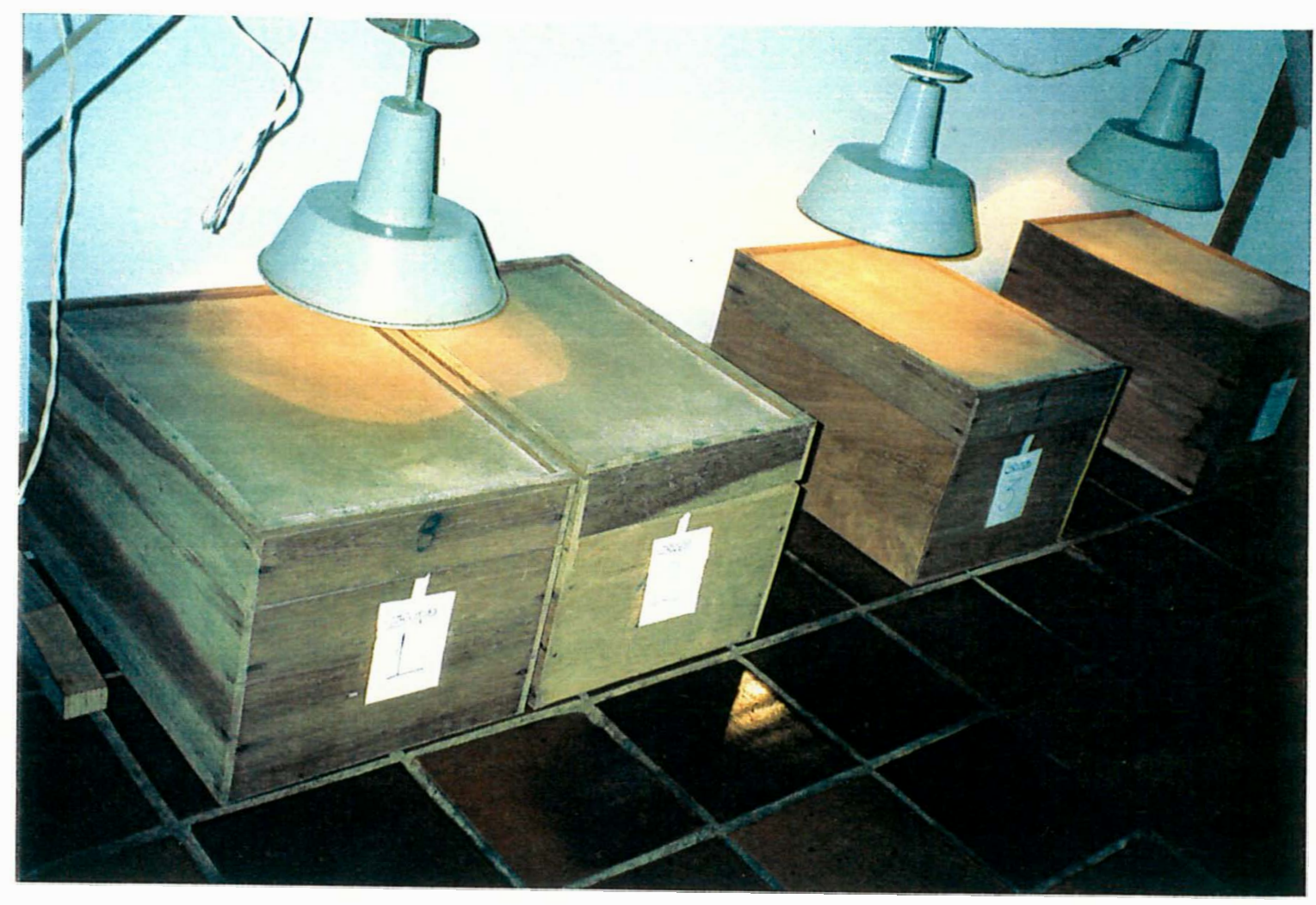

FIGURA 2 - Caixas de madeira para o alojamento das aves e disposição das lâmpadas de aquecimento. 


\subsection{Métodos}

Colonização cecal pela Salmonella (coleta do material): Os pintainhos foram sacrificados 72 horas após o alojamento pelo deslocamento cervical. 0 abdômen de cada ave foi aberto e o conteúdo cecal coletado assepticamente e transferido para frascos individuais previamente esterilizados e tarados. Cada ave funcionou como uma repetição (unidade experimental). A seguir, os frascos foram pesados e através do peso do conteúdo cecal foi determinado o volume de solução tampão de fosfato (STF), com $\mathrm{pH} 7,4$, para obter a primeira diluição $\left(10^{-1}\right)$. Posteriormente o conteúdo dos frascos foram homogeneizados e acondicionados em um refrigerador até o momento de plaqueamento.

Plaqueamento: A partir da diluição $10^{-1}$ foram produzidas mais cinco diluições decimais seriadas. As diluições foram semeadas em ágar Verde Brilhante (VB) contendo ácido nalidixico $(100 \mathrm{ug} / \mathrm{ml})$ e espectińomicina $(100 \mathrm{ug} / \mathrm{ml})$. As placas foram incubadas a $37^{\circ} \mathrm{C}$, durante 24 horas,

A avaliação da presença de Salmonella no conteúdo cecal das aves foi efetuada pela estimativa de contagem de bactéria, seguindo o modelo adotado por BERCHIERI Jr. \& BARROW (1990). O resultado obtido foi o número de colônias por grama (ufc/g). Posteriormente, estes resultados foram transformados para logaritmo $\left(\log _{10}\right)$.

A contagem de Salmonella na ração, experimento I, foi realizada pelo método do número mais provável (NMP), segundo GALTON et al. (1968), com diluições decimais em série de três tubos em caldo nutriente. Na sequência, $1 \mathrm{ml}$ de cada frasco foi inoculado em $10 \mathrm{ml}$ de caldo selenito-novobiocina (SN). Os 
meios foram incubados a $37^{\circ} \mathrm{C}$, durante vinte e quatro horas. A partir do caldo $\mathrm{SN}$, as amostras foram plaqueadas em ágar Verde Brilhante tratado com o ácido nalidixico e novobiocina. Os resultados obtidos foram transformados em número mais provável de Salmonella / g de ração.

Foram conduzidos oito experimentos, sendo um experimento in vitro e os demais experimentos in vivo. Nos experimentos in vivo os tratamentos foram fornecidos às aves aleatoriamente. Não foi utilizada análise estatística neste trabalho porque o objetivo não foi o de reduzir o nivel de Salmonella, mas eliminá-la completamente. Uma redução de Salmonella poderia ser significativa, mas as aves continuariam sendo portadoras. 


\section{Experimento I $\rightarrow$ in vitro}

Objetivo: Desenvolver uma fórmula contendo os ácidos fórmico, propiônico e lático, este último adicionado com o objetivo de baratear a fórmula, e testar os seus efeitos sobre a Salmonella typhimurium inoculada na ração.

\section{Tratamentos:}

$A=$ ração contaminada sem tratamento, controle;

$\mathrm{B}=$ ração contaminada $+0,1 \%$ da solução de ácidos graxos de cadeia curta, $(A G C C)^{*}$

$C=$ ração contaminada $+0,2 \%$ da solução de $A G C C$;

$D=$ ração contaminada $+0,4 \%$ da solução de $A G C C$.

* $\rightarrow$ Solução de AGCC : $50 \%$ ácido propiônico, $25 \%$ ácido fórmico e $25 \%$ ác. lático.

\section{Experimento II $\rightarrow$ in vivo}

Objetivo: Ainda que solução de AGCC* utilizada no experimento I não tenha sido eficiente, foi avaliado se haviam diferenças na ação quando testada in vivo comparada à sua ação in vitro. Para este estudo foram utilizados 16 pintainhos por tratamento. Nos demais experimentos foram utilizados 10 pintainhos/tratamento .

\section{Tratamentos:}
A : Ração contaminada $+0,4 \%$ de AGCC *;
B : Ração contaminada não tratada, controle.

*A mesma solução utilizada no Experimento I. 


\section{Experimento III $\rightarrow$ in vivo}

Objetivo: A solução composta pelos ácidos propiônico, fórmico e lático não foi eficiente em reduzir a Salmonella typhimurium. Foi desenvolvida uma nova fórmula empregando somente os ácidos fórmico e propiônico, por serem estes os ácidos mais utilizados na maioria dos trabalhos descritos na literatura científica. Neste experimento foram utilizadas concentrações maiores da solução, para posteriormente, em caso de sucesso, testar dosagens menores e mais econômicas.

\section{Tratamentos:}
A : Ração contaminada $+0,4 \%$ da solução de AGCC **;
B : Ração contaminada + 0,8\% da solução de AGCC;
C : Ração contaminada sem tratamento, controle.
** $\rightarrow$ Solução de AGCC: $70 \%$ ácido fórmico e 30\% ácido propiônico.

\section{Experimento IV $\rightarrow$ in vivo}

Objetivo: Uma vez obtidos resultados positivos com a solução de AGCC empregada no experimento III, foi conduzido um estudo para testar se a mesma permaneceria efetiva contra a Salmonella typhimurium, quando utilizada em concentrações menores na ração,

\section{Tratamentos:}
A : Ração contaminada $+0,1 \%$ de solução de AGCC **;
$B$ : Ração contaminada $+0,2 \%$ de solução de $A G C C$;
C : Ração contaminada $+0,4 \%$ de solução de $A G C C$;
D : Ração contaminada sem tratamento, controle.
** $\rightarrow$ Solução de AGCC: $70 \%$ ácido fórmico e $30 \%$ ácido propiônico. 


\section{Experimento $\mathbf{V} \rightarrow$ in vivo}

Objetivo: Diante da eficiência constatada com a mistura dos ácidos fórmico e propiônico, foi avaliado o uso isolado de cada um dos ácidos na mesma proporção em que foram utilizados na solução. Isto permitiria determinar:

1 - Se algum dos ácidos foi mais eficiente sobre a Salmonella typhimurium do que o outro;

2 - Se havia sinergismo entre eles.

\section{Tratamentos:}
A : Ração contaminada $+0,4 \%$ de ácido fórmico*;
B : Ração contaminada $+0,8 \%$ de ácido fórmico;
C : Ração contaminada $+0,4 \%$ de ácido propiônico*;
D : Ração contaminada $+0,8 \%$ de ácido propiônico;
E : Ração contaminada sem tratamento, controle.

- $\rightarrow$ Solução de ácido fórmico: $70 \%$ ácido fórmico e $30 \%$ água destilada.

$\rightarrow$ Solução de ácido propiônico: $30 \%$ de ácido propiônico e $70 \%$ de água destilada.

\section{Experimento $\mathrm{VI} \rightarrow$ in vivo}

Objetivo: Este experimento empregou a mistura dos ácidos fórmico e propiônico, que foi eficiente à $0,4 \%$ eliminando a Salmonella typhimurium e testou a mesma 
solução sobre as cepas $S$. agona, $S$. enteritidis e $S$. infantis. Foi utilizada a mesma metodologia empregada nos estudos com a Salmonella typhimurium.

As matérias-primas de origem animal são consideradas uma das principais fontes de contaminação por Salmonella em rações para aves. Ainda neste experimento, uma amostra de farinha de carne esterilizada em autoclave durante vinte minutos, a $121^{\circ} \mathrm{C}$ e posteriormente, inoculada com $\mathrm{S}$. typhimurium foi tratada com a solução de AGCC a 0,8\%. A farinha de carne foi incorporada à uma ração previamente esterilizada a uma proporção de $10 \%$. O tratamento controle consistiu de uma ração também previamente esterilizada contendo $10 \%$ da mesma farinha de carne inoculada, porém não tratada. $O$ objetivo foi determinar se o tratamento de uma fonte de salmonelas na ração seria suficiente para eliminar o problema na ração.

\section{Tratamentos:}

A : Ração contaminada com S. agona + $0,4 \%$ de solução de AGCC*;

B : Ração contaminada com S. agona, controle;

C : Ração contaminada com S. enteritidis $+0,4 \%$ de solução de AGCC;

D : Ração contaminada com S. enteritidis, controle;

$E$ : Ração contaminada com S. infantis + $0,4 \%$ de solução de AGCC;

F : Ração contaminada com S. infantis, controle;

G: Ração com $10 \%$ de Farinha de Carne contaminada com S. typhimurium + $0,8 \%$ de solução de $A G C C$;

H : Ração com $10 \%$ de Farinha de Carne contaminada com S. typhimurium, controle.

* $\rightarrow$ Solução de AGCC: $70 \%$ ácido fórmico e 30\% ácido propiônico 
Experimento VII $\rightarrow$ in vivo

Objetivo: Os resuldos obtidos no experimento VI demonstraram que não há um comportamento uniforme das diferentes cepas de Salmonella, frente à solução de ácidos graxos de cadeia curta. $O$ crescimento da $S$. enteritidis e $S$. infantis não foi afetado pela associação dos ácidos fórmico e propiônico usadas a um nivel de $0,4 \%$ nas rações. No entanto, a $S$. agona foi sensivel, não tendo sido observado crescimento de colônias. Neste experimento foi utilizada uma concentração da solução dos AGCC a $0,8 \%$, para tratar as rações contaminadas com a $S$. enteritidis e $S$. infantis.

\section{Tratamentos:}

A : Ração contaminada com $S$. enteritidis $+0,8 \%$ de solução AGCC *;

B : Ração contaminada com S. enteritidis, controle;

C : Ração contaminada com $S$. infantis + $0,8 \%$ de solução AGCC;

D : Ração contaminada com S. infantis, controle.

* $\rightarrow$ Solução de AGCC : $70 \%$ de ácido fórmico e $30 \%$ de ácido propiônico.

\section{Experimento VIII $\rightarrow$ in vivo}

Objetivo: $O$ crescimento da $S$. infantis não foi afetado pelo tratamento com a solução de AGCC utilizada à $0,8 \%$, no experimento VII. No presente experimento houve uma redução no nivel de bactérias inoculadas para aproximadamente $1,2 \times 10^{3} \mathrm{ufc} / \mathrm{g}$ de ração e um posterior tratamento com $0,8 \%$ da solução de AGCC. O objetivo foi determinar se o tratamento para S. infantis é dose dependente, ou seja, depende do número de bactérias presentes na ração. 
Tratamentos:

A : Ração contaminada com S. infantis* + 0,8\% de solução de AGCC ${ }^{\star *}$;

B : Ração contaminada com S. infantis, controle.

* $\rightarrow$ Aproximadamente $1,2 \times 10^{3} \mathrm{ufc} / \mathrm{g}$ de ração.

${ }^{\star *} \rightarrow$ Solução de AGCC : $70 \%$ ácido fórmico e 30\% ácido propiônico. 


\section{4 - RESULTADOS}

\section{Experimento I :}

A contagem de S. typhimurium na ração foi realizada pelo número mais provável (N.M.P.). O total obtido de amostras positivas (+) e negativas (-) foi transferido para uma tabela apropriada e comparado com a tabela do Food \& Drug Administration, F.D.A., segundo as diferentes diluiçōes. Os dados foram posteriormente transformados para logarítmo, $\mathrm{n}^{0}$ bactérias/g. Os resultados são apresentados na Tabela 1.

Houve uma redução na contagem de bactérias vinte quatro horas após o início do experimento. Porém, esta redução não pode ser atribuida aos tratamentos, já que também ocorreu no grupo controle. As rações tratadas com a solução de ácidos graxos de cadeia curta não apresentaram redução na contaminação inicial por S. typhimurium, quando comparadas à ração controle.

\section{Experimento II :}

Confirmando os resultados obtidos in vitro, o tratamento com $0,4 \%$ da solução de AGCC não foi eficiente na redução da contaminação inicial por $S$. typhimurium em aves. A Tabela 2 apresenta a estimativa de contagem de colônias, sendo que os dados foram transformados em logaritmo. 
Tabela 1 - Experimento I - Contagem do NMP de S. typhimurium, considerando os diferentes períodos de contato da ração com a solução de AGCC. Resultados transformados em $\log _{10}$.

\begin{tabular}{|c|c|c|c|c|c|}
\hline Trat. & 0 horas ${ }^{*}$ & $\begin{array}{c}24 \\
\text { horas }\end{array}$ & $\begin{array}{c}42 \\
\text { horas }\end{array}$ & $\begin{array}{c}72 \\
\text { horas }\end{array}$ & 05 dias \\
\hline $\begin{array}{l}\text { Ração contaminada não } \\
\text { tratada(controle) }\end{array}$ & 4,38 & 2,63 & 2,32 & 2,63 & 2,36 \\
\hline $\begin{array}{l}\text { Ração contaminada + } \\
0,1 \% \text { sol. de } A G C C^{\star \star}\end{array}$ & 4,18 & 3,38 & 3,36 & 3,38 & 2,88 \\
\hline $\begin{array}{c}\text { Ração contaminada + } \\
0,2 \% \text { sol. de AGCC }\end{array}$ & 4,38 & 2,97 & 3,36 & 2,63 & 2,97 \\
\hline $\begin{array}{c}\text { Ração contaminada + } \\
0,4 \% \text { sol. de AGCC }\end{array}$ & 5,18 & 2,97 & 3,36 & 3,38 & 2,97 \\
\hline
\end{tabular}

Tabela 2 - Experimento II - Estimativa de contagem de S. typhimurium no conteúdo cecal de pintainhos. Resultados em $\log _{10}$.

Tratamentos

Ração Controle

Ração + 0,4\% de sol. AGCC
Médias - $\log _{10}$

$8,82(6,2-11,0)$

$8,05(4,7-9,3)^{\star \star}$

* Solução de AGCC: $50 \%$ ácido propiônico + 25\% ácido fórmico

$+25 \%$ ácido lático

* Valores mínimo e máximo obtido na contagem de S. typhimurium. 


\section{Experimento III :}

Como pode ser observado na Tabela 3, não houve crescimento de colônias de S. typhimurium no conteúdo cecal de aves submetidas aos tratamentos A e B. Somente o grupo controle apresentou crescimento nas placas. Os dados obtidos sugerem que uma mistura de $70 \%$ de ácido fórmico e $30 \%$ de ácido propiônico, nas concentrações de 0,4 e $0,8 \%$, pode ser utilizada para o controle de $S$. typhimurium em rações para aves.

Tabela 3 - Experimento III - Estimativa de contagem de S. typhimurium no conteúdo cecal de pintainhos. Resultados em $\log _{10}$.

Tratamentos

Ração Controle

Ração + 0,4\% de solução de AGCC*

Ração + 0,8\% de solução de AGCC
Média - $\log _{10}$

$7,72(3,33-9,72)$

menos de $100 \mathrm{ufc} / \mathrm{g}$

menos de $100 \mathrm{ufc/g}$

* Solução de AGCC: $70 \%$ ácido fórmico + $30 \%$ ácido propiônico

\section{Experimento IV :}

As concentrações inferiores a $0,4 \%$ da mistura dos ácidos fórmico e propiônico se mostraram ineficientes, não eliminando a Salmonella typhimurium inoculada na ração. Nos resultados demonstrados na Tabela 4, pode ser observada a 
eficiência da solução de AGCC quando usada a $0,4 \%$, confirmando os resultados obtidos no experimento III.

Tabela 4 - Experimento IV - Estimativa de contagem de Salmonella typhimurium no conteúdo cecal de pintainhos.

Tratamentos $\quad$ Médias - $\log _{10}$

$\begin{array}{cc}\text { Controle } & 7,98(6,17-9,14) \bullet \\ 0,1 \% \text { de solução de AGCC } & 7,86(4,95-8,59) \\ 0,2 \% \text { de solução de AGCC } & 6,32(3,25-8,68) \\ 0,4 \% \text { de solução de AGCC } & \text { menos de 100 ufc/g }\end{array}$

$\rightarrow$ Solução de AGCC : $70 \%$ ácido fórmico + $30 \%$ ácido propiônico.

$\leftrightarrow \rightarrow$ Morte de uma ave no grupo controle

\section{Experimento V:}

Os ácidos fórmico e propiônico, quando utilizados isoladamente, foram incapazes de eliminar completamente a $S$. typhimurium na ração.

O ácido propiônico, mesmo quando adicionado na concentração de $0,8 \%$, não foi eficiente contra a Salmonella. Foram observadas pequenas reduções na contaminação inicial quando o mesmo foi empregado. 
O ácido fórmico foi mais eficiente, reduzindo em média a contagem de salmonelas em 2,73 $\log (0,4 \%)$ e $5,99 \log (0,8 \%)$, quando comparado ao grupo controle. Esta maior eficiência do ácido fórmico provavelmente seja devido à sua inclusão em uma solução mais concentrada do que o ácido propiônico. Entretanto, este ácido foi incapaz de eliminar completamente a $S$. typhimurium, mesmo quando adicionado à ração na proporção de $0,8 \%$. Esses resultados concordam com as observações sobre o sinergismo desses ácidos in vitro, fazendo com que sejam mais eficientes associados do que quando usados separadamente. Os resultados são apresentados na Tabela 5.

Tabela 5 - Experimento V - Estimativa de contagem de Salmonella typhimurium no conteúdo cecal de pintainhos. Resultados em $\log _{10}$.

\begin{tabular}{cc}
\hline Tratamentos & Média - $\log 10$ \\
\hline Controle & $7,95(6,17-9,14)$ \\
$0,4 \%$ de ácido fórmico* & $5,11\left(\mathbf{N}^{\star \star \star}-7,86\right)$ \\
$0,8 \%$ de ácido fórmico & $1,99(\mathrm{~N}-4,90)$ \\
$0,4 \%$ de ácido propiônico & $7,43(6,04-8,50)$ \\
$0,8 \%$ de ácido propiônico & $6,36(3,60-8,43)$ \\
\hline
\end{tabular}

* Solução de ácido fórmico: $70 \%$ ác. fórmico+30\% água destilada

* Solução de ácido propiônico: $30 \%$ de ác. propiônico $+70 \%$ de água destilada $\star \star \star \rightarrow N=$ menos de $100 \mathrm{ufc} / \mathrm{g}$. 


\section{Experimento VI :}

A associação dos ácidos fórmico e propiônico ao nível de $0,4 \%$ que eliminou eficientemente a $S$. typhimurium, não foi eficiente para eliminar as cepas de $S$. infantis e S. enteritidis. A S. agona foi sensivel ao tratamento, não tendo sido observado crescimento de colônias. Pode ser verificado que mesmo apresentando características semelhantes, as salmonelas podem se comportar de maneira distinta frente ao tratamento com a solução de AGCC. Os resultados são apresentados na Tabela 6.

A farinha de carne é citada como uma das principais fontes de salmonelas em rações de aves. Assim, teoricamente o tratamento de uma fonte de salmonelas na ração, seria suficiente para eliminar o problema. Contudo, o tratamento de uma ração contendo $10 \%$ de uma farinha de carne, previamente esterilizada e posteriormente inoculada com S. typhimurium, com a solução de AGCC a 0,8\% não conseguiu eliminar ou reduzir a contagem de salmonelas no conteúdo cecal dos pintainhos.

O tratamento da ração, de forma integral, mostrou ser a melhor solução para o controle das salmonelas em rações de aves.

\section{Experimento VII :}

O aumento da concentração da solução dos ácidos fórmico e propiônico para $0,8 \%$ na ração eliminou a $S$. enteritidis, não tendo sido observado crescimento de colônias. Contudo, essa mesma concentração não conseguiu 
eliminar a S. infantis, também inoculada na ração. Os resultados são apresentados na Tabela 7 .

Tabela 6 - Experimento VI - Estimativa de contagem de S. agona, S. enteritidis , S. infantis e S. typhimurium no conteúdo cecal de pintainhos. Resultados em $\log _{10}$.

Tratamentos

S. agona (controle)

S. agona $+0,4 \%$ sol. AGCC*

S. enteritidis (controle)

S. enteritidis $+0,4 \%$ de sol. AGCC

S. infantis (controle)

S. infantis $+0,4 \%$ de sol. AGCC

10\% F. Carne + S. typhimurium(controle)

$10 \%$ F. Carne + S. typhimurium + 0,8 AGCC
Média - $\log 10$

$8,84(8,50-9,25)$

$N^{* \star}$

$8,77(7,53-9,47)$

$8,36(8,04-8,77)$

$8,91(8,57-9,30)$

$7,31(2,00-8,57)$

$8,15(7,47-8,74)$

$8,24(7,62-8,75)$

* Solução de AGCC: $70 \%$ ác. fórmico+30\% ác. Propiônico

${ }^{* *} \rightarrow \mathrm{N}=$ menos de $100 \mathrm{ufc/g}$. 
Tabela 7 - Experimento VII - Estimativa de contagem de S. enteritidis e S. infantis no conteúdo cecal de pintainhos. Resultados em $\log _{10}$.

Tratamentos

S. enteritidis (controle)

S. enteritidis + $0,8 \%$ de sol. AGCC

S. infantis (controle)

S. infantis + $0,8 \%$ de sol. AGCC
Média - $\log 10$

$7,75(6,28-8,47)$

$N^{* *}$

$8,22(5,52-8,87)$

$8,62(8,27-9,04)$

* Solução de AGCC: $70 \%$ ác.fórmico + 30\% ác . propiônico

${ }^{* *} \rightarrow \mathrm{N}=$ Menos de $100 \mathrm{ufc/g}$.

\section{Experimento VIII :}

Os resultados da diluição da inoculação por $S$. infantis para aproximadamente $1,2 \times 10^{3}$ ufc /g de ração e o posterior tratamento com $0,8 \%$ da solução de AGCC, são apresentados na Tabela 8. 0 tratamento foi eficiente, conseguindo eliminar completamente a $S$. infantis. $\mathrm{O}$ grupo controle apresentou crescimento de colônias, demonstrando a capacidade de multiplicação da Salmonella nos cecos das aves 
Tabela 8 : Experimento VIII - Estimativa de contagem de S. infantis no conteúdo cecal de pintainhos. Resultados em $\log _{10}$.

\begin{tabular}{cc}
\hline Tratamentos & Média - Log10 \\
\hline S. infantis (controle) & $8,66(7,83-9,08)$ \\
S. infantis + 0,8\% de sol. AGCC & $\mathbf{N}^{\star \star}$ \\
\hline
\end{tabular}

* Solução de AGCC: $70 \%$ ác. fórmico + 30\% ác. propiônico

$*$ * $\rightarrow \mathrm{N}=$ Menos de $100 \mathrm{ufc/g}$. 


\section{V - Discussão}

Os resultados obtidos nos experimentos I e II, que podem ser denominados como fase preliminar, determinaram algumas modificações no projeto inicial deste estudo.

Nos primeiros experimentos foi analisada uma solução de ácidos graxos de cadeia curta, composta pelos ácidos fórmico, propiônico e lático, no controle de Salmonella typhimurium F98 $\mathrm{Nal}^{r}$ / Spec $^{r}$ na ração, in vitro e in vivo. Os resultados in vivo foram coincidentes com os resultados in vitro, demonstrando que a solução utilizada nos dois primeiros experimentos não inibiu o desenvolvimento da Salmonella.

Os resultados obtidos no experimento I concordam com aqueles descritos por HINTON et al. (1985); HINTON \& LINTON (1988) e HINTON (1990). Aqueles pesquisadores demonstraram que os ácidos orgânicos parecem ser inativos ou relativamente inativos na ração. A quantidade de água disponivel é insuficiente nos alimentos para que a bactéria seja ativamente metabolizada.

Nos experimentos I e II a presença do ácido lático pode ter prejudicado a ação dos ácidos propiônico e fórmico, os quais, tendo sido usados em concentrações menores na mistura, não atuaram eficientemente. LEVINE \& FELLERS (1940) observaram que o ácido lático foi menos tóxico do que o ácido acético na inibição ou destruição da Salmonella aertrycke.

Nos demais experimentos foi empregada uma nova mistura contendo $70 \%$ de ácido fórmico e $30 \%$ de ácido propiônico. Várias referências na literatura científica comprovando a eficiência destes ácidos quando usados isoladamente ou em associações (HINTON \& LINTON,1988; ROUSE et al., 1988; McHAN \& SHOTTS, 1992). 
A inibição no crescimento da S. typhimurium, obtida no experimento III, está de acordo com os resultados já relatados por vários autores, comprovando a eficiência dos ácidos fórmico e propiônico sobre a $S$. typhimurium presente no alimento de aves.

WESTERFELD et al. (1970) observaram uma completa inibição no crescimento das salmonelas inoculadas em rações esterilizadas, quando estas foram tratadas com $0,1 \%$ de um aditivo químico baseado em ácido propiônico. Igualmente, ROUSE et al. (1988) relataram que a atividade da Salmonella inoculada na ração foi reduzida, à medida em que a concentração de um aditivo comercial à base de ácido propiônico, Myco Curb, aumentou de 0 à $1 \%$ na ração.

Segundo VANDERWAL (1979), os ácidos propiônico e fórmico e combinações dos mesmos provaram ser igualmente efetivos, em niveis de $1,0 \%$. HINTON et al. (1985) não isolaram Salmonella em aves que receberam dietas contendo 0,5 e $0,75 \%$ de ácido fórmico. Os resultados obtidos por HINTON \& LINTON (1988) também comprovam a eficiência desses ácidos orgânicos. Os autores testaram dois produtos comerciais, sendo um deles à base de ácido fórmico e o outro uma mistura dos ácidos fórmico e propiônico. Ainda, McHAN et al. (1991) comprovaram a eficiência dos ácidos propiônico e fórmico na redução da $S$. typhimurium, quando usados em uma concentração de $1 \%$ na ração.

HUMPHREY \& LANNING (1988) observaram uma redução significativa na taxa de isolamento de salmonelas em pintainhos recém-nascidos, quando as reprodutoras foram alimentadas previamente com um alimento tratado com $0,5 \%$ de ácido fórmico. 
Os resultados positivos obtidos com a nova associação de ácidos orgânicos, conduziram a um estudo do efeito da adição de doses menores (Experimento IV), e também do efeito isolado dos ácidos utilizados nesta mistura (Experimento V).

Os resultados do experimento IV confirmaram a eficiência da mistura dos ácidos fórmico e propiônico sobre a Salmonella, quando utilizada à uma concentração de $0,4 \%$ na ração. Ainda, foi observado que concentrações menores desta mesma associação não conseguiram eliminar completamente as salmonelas presente na ração, ou seja, a eficiência desta mistura é dose dependente. Assim, 0,4\% é a concentração ótima a ser utilizada para a eliminação da dose inicialmente inoculada de S. typhimurium $\left(1,2 \times 10^{5} \mathrm{ufc} / \mathrm{g}\right.$ ração).

Os ácidos fórmico e propiônico quando utilizados isoladamente (Experimento V), não conseguiram eliminar eficientemente as salmonelas. Estes resultados diferem daqueles observados por WESTERFELD et al. (1970), ROUSE et al., (1988), com o uso do ácido propiônico e HINTON et al. (1985), HINTON \& LINTON (1988), usando o ácido fórmico. Contudo, aqueles autores utilizaram soluções concentradas desses ácidos, o que pode explicar a disparidade nos resultados. No experimento $\mathbf{V}$ foram utilizadas solução de ácido propiônico à $30 \%$ e solução de ácido fórmico à $70 \%$.

O ácido fórmico foi mais eficiente do que o ácido propiônico na redução da contaminação inicial por Salmonella $(2,73$ log vs 0,52 log, respectivamente na concentração de 0,4\%). Uma explicação para a maior eficiência do ácido fórmico comparado ao ácido propiônico é o fato do primeiro ter sido adicionado às rações em uma solução mais concentrada $(70 \%)$. 
O importante a ser ressaltado diante dos resultados obtidos no experimento $V$, é a comprovação de uma ação sinérgica entre estes ácidos quando utilizados em associações, tornando-os mais eficientes. O ácido fórmico mesmo a uma concentração de $0,8 \%$, foi incapaz de eliminar completamente as salmonelas; mas quando associado ao ácido propiônico foi eficiente à uma concentração de $0,4 \%$. Este sinergismo já havia sido observado in vitro (HINTON \& LINTON, 1988).

Além da Salmonella typhimurium, outros sorotipos como a $S$. enteritidis, $S$. agona e $S$. infantis estão entre aqueles de maior incidência em casos de salmonelose humana de origem alimentar. Estes sorotipos não são patogênicos para as aves, mas o são para o homem (MIRANDA et al., 1978).

A S. typhimurium é o sorotipo normalmente utilizado na maioria dos estudos publicados sobre o efeito dos ácidos graxos de cadeia curta sobre a Salmonella, por ser um dos sorotipos mais frequentemente isolado em surtos de salmonelose humana. No entanto, nos últimos anos têm sido observado o aumento na frequência de isolamentos de outros sorotipos ( $S$. enteritidis e S. infantis). A S. enteritidis se tornou o sorotipo predominante em infecções humanas nos Estados Unidos, a partir de 1990, superando a $S$. typhimurium (ALTEKRUSE et. al., 1993). Este aumento na frequência de isolamentos de S. enteritidis tem sido observado também no Brasil (ARAÚJO et al., 1995; LíRIO et al., 1995). Assim, outros sorotipos que não a S. typhimurium, estão recebendo uma maior atenção por parte dos pesquisadores.

Embora os sorotipos de Salmonella apresentem caracteristicas semelhantes, houve um comportamento diferenciado frente ao tratamento com a mistura dos ácidos fórmico e propiônico. A solução dos AGCC que à $0,4 \%$ eficientemente eliminou a $S$. Typhimurium também foi eficiente sobre a $S$. agona. Entretanto, não inibiu o crescimento de $S$. enteritidis e $S$. infantis (Experimento VI), 
demonstrando assim, que os resultados obtidos no estudo com um sorotipo, não podem ser extrapolados para outros.

O tratamento de uma farinha de carne, normalmente citada como fonte de salmonelas em rações de aves, com a solução de AGCC a $0,8 \%$, não foi suficiente para eliminar ou reduzir a contaminação inicial de $S$. typhimurium (Experimento VI). A melhor alternativa parece ser o tratamento integral da ração.

O aumento da concentração da solução de AGCC para $0,8 \%$ na ração (Experimento VII), eficientemente eliminou a S. enteritidis. Este sorotipo exigiu uma maior concentração da mistura dos ácidos fórmico e propiônico para ser eliminada. A S. infantis não foi afetada pelo aumento da concentração da solução de AGCC.

Os resultados obtidos no experimento VIII, sugerem que para a $S$. infantis o tratamento é dose dependente, ou seja, varia em função do número de bactérias presentes. A redução da inoculação inicial de $S$. infantis para aproximadamente $1,2 \times 10^{3}$ ufc/g de ração e posterior tratamento com $0,8 \%$ da solução de AGCC, resultou na inibição do crescimento de colônias no conteudo cecal das aves analisadas.

Não foram encontrados relatos na literatura científica de estudos onde os autores comparam um mesmo tratamento em diferentes sorotipos de Salmonella. $O$ que não permitiu uma comparação dos resultados obtidos nesse estudo com outros. Entretanto, os dados obtidos indicam serem estas comparações bastante importantes, e deveriam ser analisadas por outros pesquisadores quando conduzindo trabalhos com o objetivo de controlar Salmonella em aves. 
É importante lembrar que a adoção de metodologias semelhantes nos estudos conduzidos com o objetivo de observar o efeito dos AGCC sobre a Salmonella em aves poderia fornecer melhores parâmetros comparativos.

Os resultados obtidos neste trabalho foram bastante animadores quanto à ação de alguns ácidos graxos de cadeia curta sobre os sorotipos de Salmonella inoculados nas rações de aves. Porém, existem controvérsias entre alguns pesquisadores sobre a eficiência dos AGCC sobre a Salmonella. As diferenças observadas nos inúmeros trabalhos que analisam a influência de aditivos no crescimento das salmonelas são atribuidas por LINTON et al. (1985), aos diferentes sistemas experimentais utilizados. HUME et al. (1993b), estudando o efeito do ácido propiônico (na forma líquida ou na forma de pó seco), sobre a colonização da $S$. typhimurium no papo e nos cecos de pintos de corte, não observaram qualquer efeito do mesmo reduzindo a infecção por Salmonella. Resultados semelhantes haviam sido obtidos por HUME et. al. (1992).

KANIAWATI et al. (1992), estudando o efeito da suplementação da dieta com vários ácidos orgânicos (fumárico, lático e mistura dos ácidos fórmico e propiônico), sobre o desempenho de frangos de corte e a contaminação dos cecos e carcaça com $S$. typhimurium, observaram que nenhum dos tratamentos com ácidos consistentemente forneceu proteção contra a colonização por salmonelas nos cecos ou resultou em carcaças com menor grau de contaminação. Nenhum efeito adverso foi observado no desempenho das aves.

Em um outro estudo conduzido por OPITZ et al.(1993), nenhum dos cinco aditivos alimentares utilizados (Lactobacillus, lactose, ácidos orgânicos, múltiplos probióticos e pó de ovo) preveniu a colonização ou a invasão de órgãos de pintos White Leghorn pela $S$. enteritidis, quando comparados ao grupo controle. 
Nos trabalhos citados acima, os autores utilizaram os ácidos orgânicos principalmente sob a forma de um produto comercial seco. Entretanto, nos trabalhos descritos na literatura científica, os ácidos orgânicos são mais eficientes na forma líquida. Cabe ainda ressaltar, que estes produtos comerciais podem conter outras substâncias químicas não informadas no rótulo que poderiam interferir na eficiência dos ácidos.

Os resultados contrastantes talvez possam ser explicados também pelas diferentes metodologias empregadas. Nos experimentos conduzidos no presente trabalho as cepas de Salmonella foram inoculadas diretamente na ração. Nos trabalhos citados, as aves foram desafiadas oralmente com a cepa de S. typhimurium, recebendo doses de salmonelas diretamente no papo.

O efeito dos ácidos graxos de cadeia curta sobre o desempenho das aves não foi objetivo desses estudos. Porém, existem trabalhos demonstrando que a inclusão de mais de $1,0 \%$ de ácido fórmico ou $1,45 \%$ de formiato de cálcio não afetou adversamente o peso corporal , utilização do alimento ou sobrevivência das aves (IZAT et al., 1990b).

Segundo HUME et al.(1993a), parece improvável que o ácido propiônico adicionado à ração afete o trato digestivo posterior de uma maneira suficiente a criar um efetivo ambiente anti-salmonelas. Assim, os AGCC somente serão eficientes se a ave ainda não estiver contaminada pela Salmonella.

No papo, o alimento é aquecido e umidecido e o ácido orgânico inicia a sua ação sobre a Salmonella presente no alimento (NURMI \& RANTALA, 1973). Assim, parece lógico uma associação de estratégias para prevenir a infecção cecal e colonização pelas salmonelas e prevenir a recolonização do papo. Alguns estudos associando o uso da técnica de "exclusão competitiva", que consiste na administração de flora bacteriana obtida de aves adultas aos 
pintainhos (SCHLEIFER, 1992) e o tratamento do alimento com certos ácidos graxos de cadeia curta, como o ácido fórmico, demonstram serem estas estratégias compativeis para o controle de Salmonella (HINTON et al., 1991; IMPEY \& MEAD, 1989) .

Os resultados obtidos nos experimentos conduzidos neste trabalho, demonstraram a eficiência de uma solução contendo $70 \%$ de ácido fórmico e $30 \%$ de ácido propiônico, usada na proporção de 0,4 ou $0,8 \%$ dependendo do sorotipo de Salmonella e da concentração do mesmo presente na ração de aves. 


\section{VI - CONCLUSÃO}

A associação dos ácidos fórmico e propiônico, usados na proporção de $0,4 \%$ na ração de aves, demonstrou ser eficiente eliminando completamente a Salmonella typhimurium.

Os resultados obtidos nos experimentos $\mathrm{VI}$, VII e VIII demostraram que as salmonelas, mesmo apresentando características semelhantes, se comportam de maneira diferenciada frente ao tratamento com a mistura dos ácidos fórmico e propiônico.

A S. typhimiurium e S. agona foram eficientemente eliminadas pelo tratamento da ração com a solução de AGCC na proporção de $0,4 \%$. Entretanto, esta mesma concentração não inibiu o crescimento de $S$. enteritis e $S$. infantis. $O$ uso de $0,8 \%$ da solução de AGCC no tratamento das rações impediu o crescimento de $S$. enteritidis e $S$. infantis; tendo atuado sobre este último sorotipo somente após a redução do número de bactérias inicialmente inoculadas na ração para $1,3 \times 10^{3} \mathrm{ufc} / \mathrm{g}$ de ração.

Uma vez que foram usadas cepas boas colonizadoras e cepas bastante patogênicas, é possível sugerir o uso dos ácidos graxos de cadeia curta no controle de Salmonella em rações para aves.

A adição da solução de AGCC, usada a $0,8 \%$, à uma ração contendo $10 \%$ de uma farinha de carne, previamente esterilizada e posteriormente inoculada com S. typhimurium, não conseguiu eliminar ou reduzir a contagem de salmonelas no conteúdo cecal dos pintainhos. 
O tratamento da ração de uma forma integral com uma associação de AGCC foi a melhor solução para o controle das salmonelas em rações de aves.

Do ponto de vista microbiológico, é impossivel para a indústria avícola mundial assegurar estarem as rações e seus ingredientes, os animais, a carne , os ovos e o ambiente totalmente livres de Salmonella. Existem muitos pontos críticos na cadeia de produção onde a contaminação microbiológica pode ocorrer. Assim, um controle eficiente de Salmonella em aves deve envolver os setores da produção, processamento, estocagem, distribuição e comercialização. 


\section{REFERÊNCIAS BIBLIOGRÁFICAS}

1 - ALTEKRUSE, S. ; KOEHLER, J. ; HICKMAN - BRENNER, F. ; TAUXE, R. V. ; FERRIS, K. A comparison of Salmonella enteritidis phage types from egg-associated outbreaks and implicated laying flocks.

Epidemiology and Infection, Cambridge, 110: 17-22, 1993.

2 - ARAÚJO, E. ; PACHECO, M. A. S. R. ; BONI, R. F. ; FONSECA, Y. S. K. ; GELLI, D. S. ; FERNANDES, S.A. ; TAVECHIO, A. T. . Surtos alimentares por Salmonella enteritidis associados ao uso de ovo crú, em Sorocaba - S.P. In: Congresso Brasileiro de Microbiologia, 18., Santos, 1995, Anais, Sociedade Brasileira de Microbiologia, 1995, .54.

3 - BAILEY, J. S. . Symposium: Status and prospectus for control of Salmonella contamination of poultry. Poultry Science, Menasha, 67: 920, 1988.

4 - BARROW, P. A. ; TUCKER, J. F. ; SIMPSON, J. M. . Inhibition of colonization of the chicken alimentary tract with Salmonella typhimurium gram-negative facultatively anaerobic bacteria. Epidemiology and Infection, Cambridge, 98: 311-26, 1987.

5 - BARBOUR, E. K. \& NABBUT, N. H. . Isolation of Salmonella and some other potencial pathogens from two chicken breeding farms in Saudi Arabia. Avian Diseases, New Bolton Center, 26(2): 234-44, 1981. 
6 - BERCHIERI Jr. , A. \& BARROW, P.A. . Further studies on the colonization of the chicken alimentary tract with Salmonella typhimurium by pre-colonization with an avirulent mutant. Epidemiology an Infection, Cambridge, 104: 427-41, 1990.

7 - BERCHIERI, JR. ; DE CARVALHO, A. M. ; FERNANDES, S. A. ; IBA, A.M.. Detection of Salmonella typhimurium in a broiler chicken flock. Revista de Microbiologia, São Paulo, 24(3): 121-3, 1993a.

8 - BERCHIERI JR, A. ; FERNANDES, S. A. ; IRINO, K. ; QUINTANA, J. L. ; SANTOS, A.J. . Salmonella in poultry feeds in Brazil. Revista de Microbiologia, São Paulo, 24(1): 22-5, 1993b

9 - BERCHIERI Jr., A. ; ADACHI, S. Y. ; CALZADA, C. T. ; PAULILLO, A. C. ; ITURRINO, R. P. S. ; TAVECHIO, A. T. . Farinha de carne como fonte de Salmonella em granja avícola. Pesquisa Veterinária Brasileira, Rio de Janeiro, 9(1/2): 9 -12, 1989.

10 - BERCHIERI Jr., A.; IRINO, K.; NEME, S. N.; PAULILLO, A. C.; CALZADA, C. R.; FERREIRA, S. A. ; PESSOA, G. V. A. . Contaminação por Salmonella em farinhas de origem animal utilizadas no preparo de ração. Pesquisa Veterinária Brasileira, Rio Janeiro, 4(3):83-8, 1984.

11 - BORLAND, E. D. . Salmonella infection in poultry. Veterinary Record, London, 97: 406-8, 1975.

12 - BOYER Jr., C. I. ; BRUNER, D. W. ; BROWN, J. A. . Salmonella organisms isolated from poultry feed. Avian Diseases, New Bolton Center, 2: 396-401, 1958. 
13 - CALZADA, C.T. ; NEME, S.N. ; IRINO, K.; KANO, E. ; DIAS, A. M. G. ; FERNANDES, S. A. ; VAZ, T. M. I. ; PESSÔA, G. V. A. . Sorotipos de Salmonella.identificados no período de 1977-1982, no Instituto Adolfo Lutz, São Paulo, Brasil. Revista do Instituto Adolfo Lutz, São Paulo, 44(1): 1-18, 1984.

14 - CHERRINGTON, C. A.; ALLEN, V.; HINTON, M. . The influence of temperature and organic matter on the bactericidal activity of shortchain fatty acids on salmonellas. Journal of Applied Bacteriology, London, 72: 500†3, 1992.

15 - CHERRINGTON, C. A.; HINTON, M.; CHOPRA, I. . Effects of short-chain fatty acids on macromolecular synthesis in Escherichia coli. Journal of Bacteriology, Baltimore, 68: 69-74, 1990.

16 - CHERRINGTON, C. A. ; HINTON, M. ; PEARSON, G. R. ; CHOPRA , I. . Short-chain organic acids at pH 5,0 kill Escherichia coli and Salmonella spp. without causing membrane pertubation. Journal of Applied Bacteriology, London, 70: 161-5, 1991.

17- CHUNG, K. C. \& GOEPFERT, J. M. . Growth of Salmonella at low pH. Journal of Food Science, Chicago, 35: 326-8, 1970

18 - COOPER, G. L. . Salmonellosis - infections in man and the chicken: pathogenesis and the development of live vaccines - a review. Veterinary Bulletin, Wallingford, 64(2): $123-43,1994$. 
19 - CORRIER, D. E. ; HINTON Jr. , A. ; ZIPRIN, R. L. ; BEIER, R. C. ; DELOACH, J. R. . Effect of dietary lactose on cecal pH, bacteriostatic volatile fatty acids, and Salmonella typhimurium colonization of broiler chicks. Avian Diseases, New Bolton Center, 34: 617-25, 1990.

20 - COX, N. A. \& BAILEY, J. S. . Pathogens in animal feeds: means of detection and interpretation of results. In : Georgia Nutrition Conference, p. 68-72, Nov., 1991.

21 - COX, N. A. ; BAILEY, J. S. ; THOMSON, J. E. . Salmonella and other Enterobacteriaceae found in commercial poultry feed. Poultry Science, Menasha, 62: 2169-75, 1983.

22 - COX, N. A. ; BAILEY, J. S. ; BLANKENSHIP, L. C. ; MEINERSMANN, R. J. ; STERN, N. J. ; MCHAN, F. . Fifty per cent colonization dose for Salmonella typhimurium administered orally and intracloacally to young broiler chicks. Poultry Science, Menasha, 69 : 1809-12, 1990.

23 - DE ALMEIDA, P. F. ; DA SILVA, E. N. ; ALMEIDA , R. C. C. . Contaminação e disseminação bacterianas de carcaças de frangos em abatedouros. Higiene Alimentar, Campinas, 7(27): 12-7, 1993.

24 - DeLOACH, J. R. ; OYOFO, B. A. ; CORRIER, D. E. ; KUBENA, L. F. ; ZIPRIN, R. L. ; NORMAN, J. O. . Reduction of Salmonella typhimurium concentration in broiler chickens by milk or whey. Avian Diseases, New Bolton Center, 34: 389-92, 1990. 
25 - DIXON, R. C. \& HAMILTON, P. B. . Effect of feed ingredients on the antifungal activity of propionic acid. Poultry Science, Menasha, 60: 2407-11, 1981.

26 - DUNCAN, M. S. \& ADAMS, A. W. . Effects of a chemical additive and of formaldehyde-gas fumigation on Salmonella in poultry feeds. Poultry Science, Menasha, 51: 797-802, 1972.

27 - ELLIS, E. M. . Salmonella reservoirs in animal and feeds. Journal American Oil Chemistry Societed, 46 :227, 1968.

28 - ERWIN, L. E. . Examination of prepared poultry feeds for the presence of Salmonella and other enteric organisms. Poultry Science, Menasha, 34: 215-6, 1955.

29 - GALBRAITH, N. S. . Salmonellosis in man and animals. 2. Studies on human salmonellosis in relation to infection in animals. Veterinary Record, London, 73: 1296, 1961.

30 - GALTON, M. M. ; MORRIS, G. K. ; MARTIN, W. T. . Salmonella in foods and feeds, review of isolating methods and recommended procedures. USHEW. Department of Health, Education and Welfare, 41p. , 1968.

31 - GAST, R. K. \& BEARD, C. W. . Research to understand and control Salmonella enteritidis in chicken and eggs. Poultry Science, Menasha, 72: 1157-63, 1993. 
32 - GIRÃO, F. G. F. ; NOGUEIRA, R. H. G. ; OLIVEIRA, R. L. ; FERREIRA, H. B. C.. Isolamento de Salmonella em matérias-primas, rações e materiais colhidos de aves com problemas sanitários. Arquivo Brasileiro de Medicina Veterinária e Zootecnia, Belo Horizonte, 37(3): 249-56, 1985.

33 - GOEPFERT, J. M. \& HICKS, R. . Effect of volatile fatty acids on Salmonella typhimurium. Joumal of Bacteriology, Baltimore, 97(2): 956-8, 1969.

34 - GRUMBLES , L. C. \& FLOWERS, A. I. . Epidemiology of paratyphoid infections in turkeys - Species encountered and possible sources of infection. Journal American Veterinary Medical Association, 138 : 261, 1961.

35 - HACKING, W. C. ; MITCHELL, W. R. ; CARLSON, H. C. . Salmonella investigation in an Ontario feed mill. Canadian Journal Compedium Medical, 42: 400, 1978.

36 - HINTON, M. . Antibacterial activity of short-chain organic acids.

Veterinary Record, London, 125: 370, Apr. 1990.

37 - HINTON, M. \& LINTON, A. H. . Control of Salmonella infections in broiler chickens by the acid treatment of their feed. Veterinary Record, London, 123: 416-21, Oct. 1988.

38 - HINTON, M. ; LINTON, A. H. ; PERRY, F. G. . Control of Salmonella by acid disinfection of chicks' food. Veterinary Record, London, 116: 502, May 1985. 
39 - HINTON, M. ; MEAD, G. C. ; IMPEY, C. S. . Protection of chicks against environmental challenge with Salmonella enteritidis by 'competitive exclusion'and acid-treated feed. Letters in Applied Microbiology, Oxford, 12: 69-71, 1991.

40 - HUME, M. ; AMBRUS, S. ; CORRIER, D. ; HINTON JR., A. ; DELOACH, J. . The effects of dietary propionic acid on Salmonella typhimurium colonization in the crops of broiler chicks. Poultry Science, Menasha, 71:(supl. 1): 157, 1992.

41 - HUME. M. E. ; CORRIER, D. E. ; IVIE, G. W. ; DELOACH, J. R. . Metabolism of $1^{14} \mathrm{C}$ ] propionic acid in broiler chicks. Poultry Science, Menasha, 77: 786-93, 1993a.

42 - HUME, M. E. ; CORRIER, D. E. ; AMBRUS, S. ; HINTON JR., A. ; DeLOACH, J. R. Effectiveness of dietary propionic acid in controlling Salmonella typhimurium colonization in broiler chicks. Avian Diseases, New Bolton Center, 37: 1051-6, 1993b.

43 - HUMPHREY, T. J. . Public health implications of the infection of egglaying hens with Salmonella enteritidis phage type 4. World's Poultry Science Journal, Guilford Surrey, 46: 5-13, 1990.

44 - HUMPHREY, T. J. \& LANNING, D.G. . The vertical transmission of salmonellas and formic acid treatment of chicken feed. Epidemiology and Infection, Cambridge, 100: 43-9, 1988 
45 - IMPEY, C .S. \& MEAD, C. C. . Fate of salmonellas in the alimentary tract of chicks pre-treated with a mature caecal microflora to increase colonization resistance. Journal of Applied Bacteriology, London, 66: 469-75, 1989.

46 - ISA, J. M. ; BOYCOTT, B. R. ; BROUGTHON, E. . A survey of Salmonella contamination in animal feeds and feed constituents. Canadian Veterinary Journal, Ottawa, 4(2): 41-3, 1963.

47 - IZAT, A. L.; ADAMS, M.H.; CABEL,M.C.; COLBERG, M.; REIBER, M.A.; SKINNER, J. T.; WALDROUP, P.W. . Effects of formic acid or calcium formate in feed on performance and microbiological characteristics of broilers. Poultry Science, Menasha, 69: 1876-82, 1990a.

48 - IZAT, A.L. ; TIDWELL, N. M.; THOMAS, R. A. ; REIBER, M. A. ; ADAMS, M. H. ; COLBERG, M. ; WALDROUP, P. W. . Effects of a buffered propionic acid in diets on the performance of broiler chickens and on microflora of the intestine and carcass. Poultry Science, Menasha, 69: 818-26, $1990 \mathrm{~b}$.

49 - JOHN, R. E. ; CASTALDO, D. J. ; SULIAMAN, S. . Controlling Salmonella. Feed International, Mount Morris, 11(12): 26-35, 1990

50 - JONES, F.T. ; AXTELL, R. C. ; RIVES, D. V. ; SCHEIDELER, S. E. ; TARVER JR, F.R. ; WALKER, R.L. , WINELAND, M.J. . A survey of Salmonella contamination in modern broiler production. Journal of Food Protection, Ames, 54(7): 502-7, 1991. 
51 - KANIAWATI, S. ; SKINNER, J. ; WALDROUP, P. ; WALDROUP, A. . Effects of feeding organic acids to broiler on performance and salmonellae colonization of the ceca and/ or contamination of the carcass. Poultry Science, Menasha, 71:(Supl. 1): 159, 1992.

52 - KHAN, M. \& KATAMAY, M. . Antagonistic effect of fatty acids against Salmonella in meat and bone meal. Applied Microbiology, Baltimore, 17(3): 402-4, 1969.

53 - LEVINE, A. S. \& FELLERS, C. R. . Action of acetic acid on food spoilage microorganisms. Journal of Bacteriology, Baltimore, 39: 499-513, 1940.

54 - LINTON, A. H. ; AL-ChALABY, Z. A. M. ; HINTON, M. H. . Natural subclinical Salmonella infection in chickens: A potencial model for testing the effects of various procedures on Salmonella shedding. Veterinary Record, London, 116: 361-4, 1985.

55 - LÍRIO, V. S. ; ASTONE, S. ; PIMENTEL, E. P. ; CAMARGO, D. ; STEFONI, S. ; MIYAZAWA, T. C. . Sorotipos de Salmonella isolados em alimentos. In : Congresso Brasileiro de Microbiologia, 18., Santos, 1995, Anais, Sociedade Brasileira de Microbiologia, 1995, p.54.

56 - LISTER, S. A. . Salmonella enteritidis infection in broiler and broiler breeders. Veterinary Record, London, 123(13): 350, 1988.

57 - MARSH, G. A. . The Salmonella problem. Poultry Digest, Mount Morris, 35: 417-8, 1976. 
58 - McHAN, F. . Relationship of fatty acid production and lowered ph on the recovery of Salmonella typhimurium in chicks fed selected carbohydrates. Poultry Science, Menasha, 70(Supl. 1):80, 1991

59 - McHAN, F. ; SHOTTS, E. B. ; BROWN, J. . Effect of feeding carbohydrates on the in vivo attachment of Salmonella typhimurium in chick ceca. Avian Diseases, New Bolton Center, 35: 328-31, 1991.

60 - McHAN, F. ; SHOTTS, E. B. . Effect of feeding selected short-chain fatty acids on the in vivo attachment of Salmonella typhimurium in chick ceca. Avian Diseases, New Bolton Center, 36:139-42, 1992.

61 - McHAN, F. \& SHOTTS, B. . Effect of short-chain fatty acids on the growth of Salmonella typhimurium in an in vitro system. Avian Diseases, New Bolton Center, 37: 396-8, 1993.

62 - MCHAN, F. ; COX, N. A. ; BAILEY, J. S. ; BLANKENSHIP, L. C. ; STERN, N. J. . The influence of physical and environmental variables on the in vitro attachment of Salmonella typhimurium to the ceca of chickens. Avian Diseases, New Bolton Center, 32: 215-9, 1988

63 - McILROY, S. G. ; NEILL, S. D. ; MCCRACKEN, R. M. . Control de Salmonella enteritidis por la industria avicola de Irlanda del Norte. Avicultura Profesional, Athens, 9(1): 8-10, 1991.

64 - MILES, R. D. \& BUTCHER, G. D. . Salmonella. Controlling it in the broiler, egg industries. Feedstuffs, Minnetonka, 65(42): 23-34, 1993. 
65 - MIRANDA, J. B. N.; PESSOA, G. V. A.; IRINO, K. ; CALZADA, C. T. . Ocorrência de Salmonella em farinhas utilizadas como matéria-prima na composição de rações de animais. Revista do Instituto Adolfo Lutz, São Paulo, 38(2): 157-60, 1978.

66 - MOHAMMED, M.D. \& HINTON, M. . The growth of salmonellas in hydrated animal feed supplemented with antibiotics. Letters in Applied Microbiology, Oxford, 16: 7-9, 1993.

67 - MOREHOUSE, L. G. \& WEDMAN, E. E. . Salmonella and other diseaseproducing organisms in animal by-products - A survey. Journal American Veterinary Medical Association, 139 : 989, 1961.

68 - MORRIS, G. K.; MCMURRAY, B. L.; GALTON, M. M.; WELLS, J. G. . A study of the dissemination of salmonellosis in a commercial broiler chicken operation. American Journal of Veterinary Research, Schaumburg, 30: 1413-21, 1969.

69 - NURMI, E. \& RANTALA, M. . New aspects of Salmonella infection in broiler production. Nature, London, 241: 210-1, 1973.

70 - OPITZ , H.M.; EL-BEGEARMI, M. ; FLEGG, P.; BEANE, D. . Efectiveness of five feed additives in chick infected with Salmonella enteritidis phage type 13a. Journal of Applied Poultry Research, Orono, 2(2): 147-53, 1993.

71 - PASTER, N. . A commercial scale study of the efficiency of propionic acid and calcium propionate as fungistats in poultry feed. Poultry Science, Menasha, 58: 572-6, 1979. 
72 - PATTEN, J. D. \& WALDROUP, P. W. . Use of organic acids in broiler diets. Poultry Science, Menasha, 67: 1178-82, 1988.

73 - PESSÔA, G.V.A.; IRINO, K.; MELLES, C.E.A.; CALZADA, C.T.; RASKIN, M.; KANO, E. . Ocorrência de bactérias enteropatogênicas em São Paulo no septênio 1970-76. II - O surto epidêmico de Salmonella typhimurium em São Paulo. Revista do Instituto Adolfo Lutz, São Paulo, 38(2): 107-27, 1978.

74 - ROBERTS, T. . Salmonellosis control: estimated economic costs. Poultry Science, Menasha, 67: 936-43, 1988

75 - ROUSE, J. ; ROLOW, A. ; NELSON, C. E. . Research note: Effect of chemical treatment of poultry feed on survival of Salmonella. Poultry Science, Menasha, 67: 1225-8, 1988.

76 - SCHLEIFER, J. . Se control in production topic of seminar on research. Poultry Digest, Mount Morris, 51: 40-1, Apr. 1992.

77 - SCHULTZ, L. J. ; RIEMANN, H. P. ; ESTEBAN, E. . Effect of mold inhibitors on Salmonella colonization in broiler chicks. Poultry Science, Menasha, 70(Supl. 1): 106, 1991.

78 - SHANE, S. M. . Biological control of intestinal Salmonella infection. Zootecnica International, Madrid, p. 40-1, Apr. 1992.

79 - SMYSER, C. F. \& SNOEYENBOS, G. H. . Evaluation of organic acids and other compounds as Salmonella antagonists in meat and bone meal. Poultry Science, Menasha, 58: 50-4, 1979. 
80 - SMITH, H. W. \& TUCKER, J.F. . The effect of antibiotics therapy on the cecal excretion of Salmonella typhimurium by experimentally infected chicken. Journal of Hygiene, Cambridge, 75: 275-92, 1975.

81 - TAUNAY, A. E. ; FERNANDEZ, S. A. ; TAVECHIO, A. T. ; NEVES, B. C. ; DIAS, A. M. G. ; IRINO, K. The role of public health laboratory in the problem of salmonellosis in São Paulo, Brazil, Revista do Instituto de Medicina Tropical, São Paulo, 38 (2): 119-127, 1996.

82 - VANDERWAL, P. . Salmonella control of feedstuffs by pelleting or acid treatment. World's Poultry Science Journal, Guilford Surrey, 35(2): 70-8, 1979.

83 - VAUGHN, J. B. ; WILLIAMS, L. P. ; LEBLANC, D. R. ; HELSDON, H. L. ; TAYLOR, C. . Salmonella in a modern broiler operation: a longitudinal study. American Journal Veterinary Research, Schaumburg, 35(5): 737-41, 1974.

84 - VILLEGAS, P. . Posibilidades para el control de Salmonella. Avicultura Profesional, Athens, 10(3): 123-4, 1993.

85 - WATSON, W. A. \& BROWN, J. M. . Salmonella infection and meat hygiene: poultry meat. Veterinary Record, London, 96: 351-3, 1975.

86 - WESTERFELD, B. L. ; ADAMS, A. W. ; ERWIN, L. E. ; DEYOE, C. W. . Effect of a chemical additive on Salmonella in poultry feed and host birds. Poultry Science, Menasha, 49: 1319-23, 1970. 
87 - WILLIAMS, J. E. . Salmonellas in poultry feeds - A worldwide review. Part I \& II. World's Poultry Science Journal, Guilford Surrey, 37: $6-25,1981 a$.

88 - WILLIAMS, J. E. . Salmonellas in poultry feeds - A worlwide review. Part III. World's Poultry Science Journal, Guilford Surrey, 37: 97-105, 1981b.

89 - XU, Y. M. ; PEARSON, G. R. ; HINTON, M. . The colonization of the alimentary tract and visceral organs of chicks with salmonellas following challenge via the feed: bacteriological findings. British Veterinary Journal, London, 144(4): 403-10, 1988. 